San Jose State University

SJSU ScholarWorks

Master's Theses

Master's Theses and Graduate Research

Spring 2016

\title{
The Impact of Performance Management System Characteristics on Perceived Effectiveness of the System and Engagement
}

Laura Ricci

San Jose State University

Follow this and additional works at: https://scholarworks.sjsu.edu/etd_theses

\section{Recommended Citation}

Ricci, Laura, "The Impact of Performance Management System Characteristics on Perceived Effectiveness of the System and Engagement" (2016). Master's Theses. 4702.

DOI: https://doi.org/10.31979/etd.qh7m-s97u

https://scholarworks.sjsu.edu/etd_theses/4702

This Thesis is brought to you for free and open access by the Master's Theses and Graduate Research at SJSU ScholarWorks. It has been accepted for inclusion in Master's Theses by an authorized administrator of SJSU ScholarWorks. For more information, please contact scholarworks@sjsu.edu. 
THE IMPACT OF PERFORMANCE MANAGEMENT SYSTEM CHARACTERISTICS ON PERCEIVED EFFECTIVENESS OF THE SYSTEM AND ENGAGEMENT

\author{
A Thesis \\ Presented to \\ The Faculty of the Department of Psychology \\ San José State University
}

\author{
In Partial Fulfillment \\ of the Requirements for the Degree \\ Master of Science
}

by

Laura M. Ricci

May 2016 
(C) 2016

Laura M. Ricci

ALL RIGHTS RESERVED 
The Designated Thesis Committee Approves the Thesis Titled

THE IMPACT OF PERFORMANCE MANAGEMENT SYSTEM CHARACTERISTICS ON PERCEIVED EFFECTIVENESS OF THE SYSTEM AND ENGAGEMENT

by

Laura M. Ricci

APPROVED FOR THE DEPARTMENT OF PSYCHOLOGY

SAN JOSÉ STATE UNIVERSITY

May 2016

$\begin{array}{ll}\text { Dr. Howard Tokunaga } & \text { Department of Psychology } \\ \text { Dr. Megumi Hosoda } & \text { Department of Psychology } \\ \text { Susana Fernandez } & \text { Intuit Inc. }\end{array}$




\title{
ABSTRACT \\ THE IMPACT OF PERFORMANCE MANAGEMENT SYSTEM CHARACTERISTICS ON PERCEIVED EFFECTIVENESS OF THE SYSTEM AND ENGAGEMENT
}

\author{
by Laura M. Ricci
}

The purpose of this study was to comprehensively examine performance management systems to determine the characteristics that are most influential in predicting desirable organizational outcomes. Results of an online survey administered to 159 participants revealed that the four performance management system categories significantly predicted employees' perceived effectiveness of their performance management system and employee engagement. The activities category was found to be the strongest predictor of perceived effectiveness and employee engagement. Four performance management system characteristics significantly led employees to perceive their performance management system to be effective and be engaged at work. These four performance management system characteristics include systems that focused on the results employees achieved, evaluated employees on their contextual performance, facilitated the construction of individual development plans for employees, and allowed for participative decision making between managers and subordinates. The results suggested that organizations should implement these characteristics into their performance management system to increase perceived effectiveness of the system and employee engagement. 


\section{ACKNOWLEDGEMENTS}

First I would like to thank my thesis committee for their dedicated efforts and constant support in helping me complete this thesis. Howard Tokunaga, thank you for your sage guidance and unrelenting encouragement throughout the thesis process and my time as a graduate student at SJSU. I would also like to thank Megumi Hosoda for her meticulous eye in reading my paper and for all of the support she offered me while going through the graduate program. I would also like to express my gratitude to Susie Fernandez for continuously encouraging me to finish my thesis.

I would also like to give special thanks to my family and friends. Dad, thank you for always believing in my abilities to accomplish my goals, without your support I would not have been able to achieve this monumental milestone. Michael, thank you for being an exemplary role model; the example you set for me greatly contributed to my motivation to be my best self. Mom, thank you for your constant encouragement and support. Lastly, I want to thank Justin Shoolery for his patience, love, and support, without which I would not have been able to achieve this accomplishment. 


\section{TABLE OF CONTENTS}

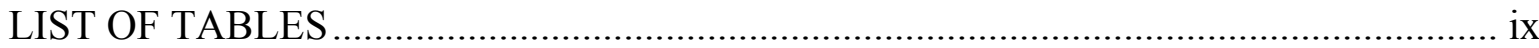

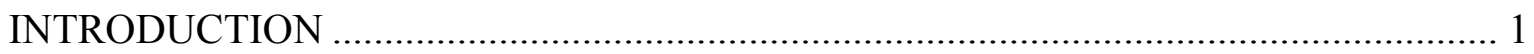

Performance Management …………………...................................................... 1

Characteristics of Performance Management Systems.......................................... 2

Purpose of the performance management system.......................................... 3

Performance measures ............................................................................ 5

Performance management system activities .............................................. 7

Structure of performance management systems ……….............................. 8

Perceived Effectiveness of Performance Management Systems ............................... 10

Purpose of the performance management system......................................... 12

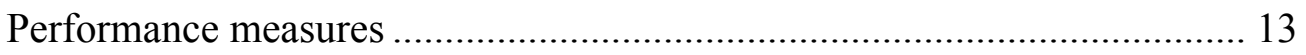

Performance management system activities ................................................ 14

Structure of performance management systems ……………………......... 15

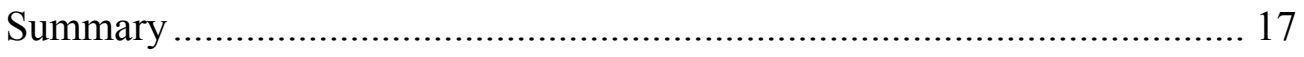

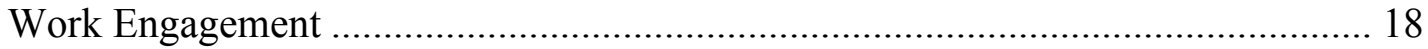

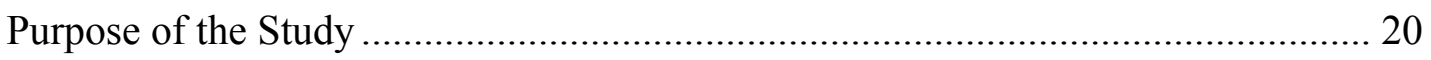

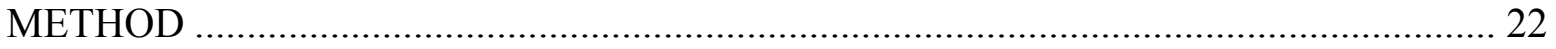

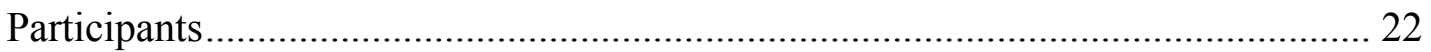

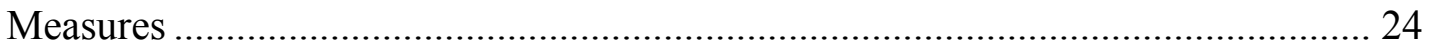

Performance management system characteristics........................................ 24

Purpose of the performance management system.............................. 24 


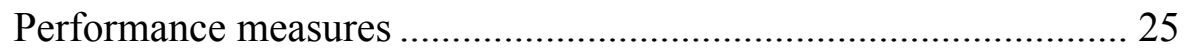

Performance management system activities .................................... 26

Structure of performance management systems ............................... 27

Perceived effectiveness of performance management systems .................... 29

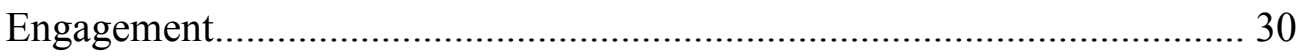

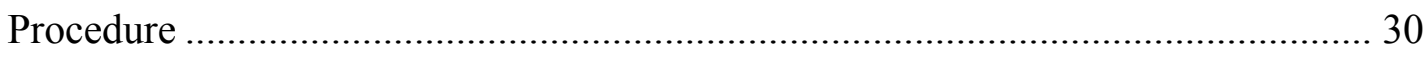

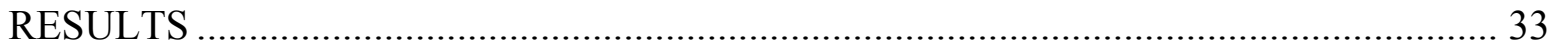

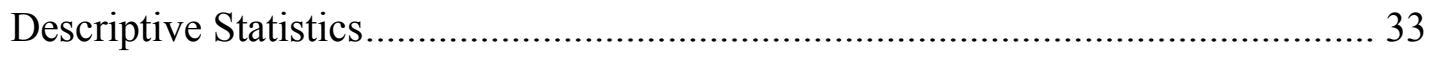

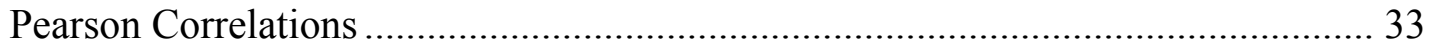

Perceived effectiveness of performance management systems ..................... 33

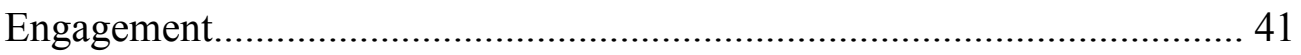

Standard Multiple Regression Analysis: Perceived Effectiveness ............................ 44

Performance management system categories …………............................... 44

Purpose of the performance management system......................................... 46

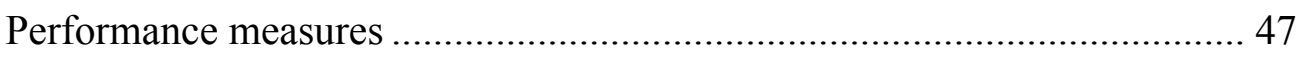

Performance management system activities .................................................. 49

Structure of performance management systems ………............................. 50

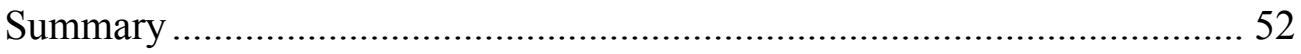

Standard Multiple Regression Analysis: Engagement................................................ 53

Performance management system categories ……………………………..... 53

Purpose of the performance management system......................................... 54

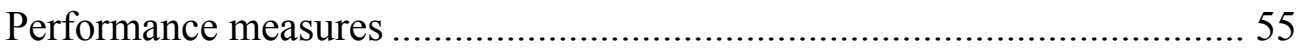


Performance management system activities ........................................ 56

Structure of performance management systems ................................... 57

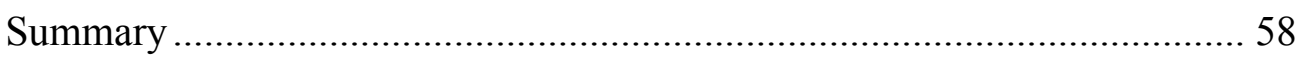

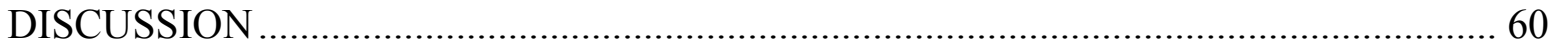

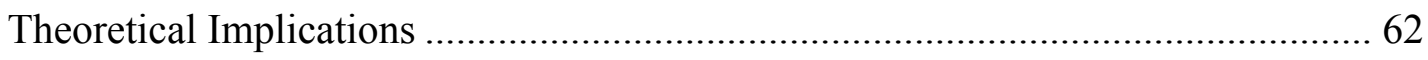

Perceived effectiveness of performance management systems .................. 62

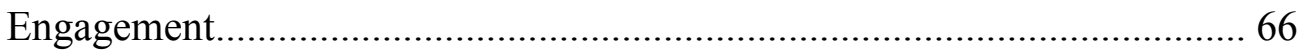

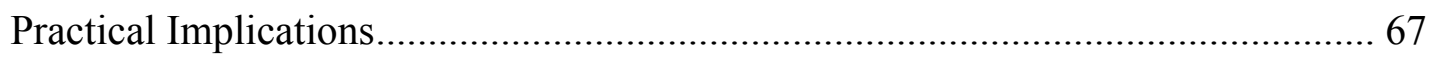

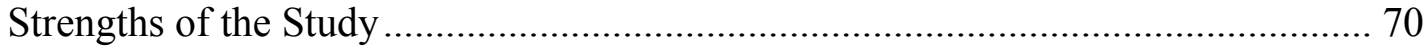

Limitations of the Study and Directions for Future Research .............................. 71

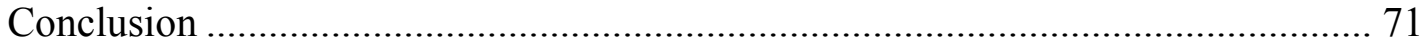

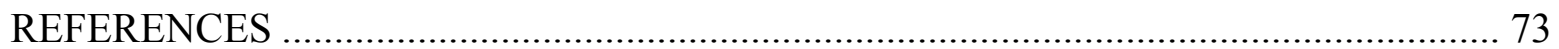




\section{LIST OF TABLES}

Table 1. Performance Management System Characteristics. 4

Table 2. Demographic Characteristics

Table 3. Means and Standard Deviations for Performance Management System Characteristics, Perceived Effectiveness, and Engagement.

Table 4. Pearson Correlations Among Performance Management System Categories, Perceived Effectiveness of the Performance Management System, and Engagement 36

Table 5. Pearson Correlations Among Performance Management System Purposes, Perceived Effectiveness of the Performance Management System, and Engagement

Table 6. Pearson Correlations Among Performance Management System Performance Measures, Perceived Effectiveness of the Performance Management System, And Engagement.

Table 7. Pearson Correlations Among Performance Management System Activities, Perceived Effectiveness of the Performance Management System, and Engagement

Table 8. Pearson Correlations Among Structural Performance Management System Characteristics, Perceived Effectiveness of Performance Management Systems, and Engagement.

Table 9. Standard Multiple Regression Analysis with Performance Management System Categories to Predict Perceived Effectiveness of the Performance Management System.

Table 10. Standard Multiple Regression Analysis with Performance Management System Purposes to Predict Perceived Effectiveness of the Performance Management System. 46

Table 11. Standard Multiple Regression Analysis with Performance Measure Characteristics to Predict Perceived Effectiveness of the Performance Management System 48

Table 12. Standard Multiple Regression Analysis with Performance Management System Activities to Predict Perceived Effectiveness of the Performance Management System 
Table 13. Standard Multiple Regression Analysis with Structural Performance Management System Characteristics to Predict Perceived Effectiveness of the Performance Management System

Table 14. Standard Multiple Regression Analysis with Performance Management System Categories to Predict Engagement 54

Table 15. Standard Multiple Regression Analysis with Performance Management System Purposes to Predict Engagement

Table 16. Standard Multiple Regression Analysis with Performance Measure Characteristics to Predict Engagement 56

Table 17. Standard Multiple Regression Analysis with Performance Management System Activities to Predict Engagement. 57

Table 18. Standard Multiple Regression Analysis with Structural Performance Management System Characteristics to Predict Engagement 58 


\section{Introduction}

Performance management systems are crucial to enhance organizational performance (Buchner, 2007) and effectiveness (Cardy, 2004; as cited by Gruman \& Saks, 2011). However, despite the touted benefits of utilizing performance management systems, 70\% of implementations of these systems fail (McCunn, 1998). In order to put successful performance management systems in place, organizations must know what characteristics of these systems are most instrumental in producing beneficial organizational outcomes. Although previous research has examined the impact of small sets of performance management characteristics, few studies have been conducted that define a comprehensive list of characteristics to determine the ones most predictive of positive organizational outcomes such as perceived effectiveness of the system and engagement. Therefore, the purpose of this study was to comprehensively evaluate performance management system characteristics to identify those with the ability to predict perceived effectiveness of the system and employee engagement.

\section{Performance Management}

Performance management is one of the many practices that comprise talent management. Collings and Mellahi (2009) defined talent management as

activities and processes that involve the systematic identification of key positions which differentially contribute to the organization's sustainable competitive advantage, the development of a talent pool of high potential and high performing incumbents to fill these roles, and the development of a differentiated human resource architecture to facilitate filling these positions with competent incumbents and to ensure their continued commitment to the organization (p. 304).

Talent management consists of standard human resources practices, functions, and activities, including recruitment, selection, training, and performance management 
(Byham, 2001; Chowanec \& Newstrom, 1991; Heinen \& O’Neill, 2004; Mercer, 2005; Oslen, 2000; as cited by Lewis \& Heckman, 2006).

Performance management is one component of talent management and has been defined as the measurement and management of employee and organizational performance, with the ultimate goal of improving organizational effectiveness (DeNisi, 2000). As part of performance management, managers work together with their employees to set performance expectations, measure and review performance results, and reward performance (DeNisi). Specifically, performance management consists of the following elements: setting performance goals at the organizational, departmental, team, and individual level, conducting performance appraisals, developing systems to provide rewards, feedback, and coaching, and measuring the effectiveness of performance management systems (Roberts, 2003).

Performance management systems can be defined by these interrelated and independent performance management elements that influence one another to increase employee and organizational performance in order to ultimately enhance organizational effectiveness. Each of the elements can be present alone and can be considered performance management. However, performance management systems consist of several performance management elements that work together to achieve the common goal of improving organizational performance and effectiveness.

\section{Characteristics of Performance Management Systems}

Performance management system characteristics can be grouped into four categories: the purpose of the system, performance measures, activities, and structural 
characteristics. All of the characteristics in each of these four categories are presented in Table 1 and discussed below.

Purpose of the performance management system. The purpose of a performance management system reflects the main objectives and guiding principles an organization has for the system to help it gain a competitive advantage (Dewettinck, 2008). Most commonly, organizations use performance management systems for three main purposes: to achieve results, develop employees, or accomplish administrative purposes. Performance management systems with a results oriented purpose focus on performance outcomes and view employees as a means to achieve organizational goals, such as increasing revenue or company sales (Dewettinck; Truss, Gratton, Hope-Hailey, McGovern, \& Stiles, 1997). Performance management systems with a developmentoriented purpose focus primarily on employee development under the assumption that empowering employees through development leads to better performance and subsequently a competitive advantage (Dewettinck; Truss et al.). Performance management systems that focus mainly on administrative purposes provide organizations with valuable information for human resource-related decisions, including promotions, pay raises, and terminations (Biron, Farndale, \& Paauwe, 2011). These decisions signal to employees what performance is valued by the organization, which helps guide employee behaviors (Biron et al.). 
Table 1

Performance Management System Characteristics

\begin{tabular}{|c|c|}
\hline Characteristic & Description \\
\hline \multicolumn{2}{|l|}{ Purpose of performance management systems } \\
\hline Results oriented & Focus on performance outcomes \\
\hline Development-oriented & Focus on employee development \\
\hline Administrative purposes & Focus on administrative purposes to inform decisions \\
\hline \multicolumn{2}{|l|}{ Performance measures } \\
\hline Relevance of performance measures & Extent performance measures are related to the job \\
\hline Task performance & Fundamental technical activities important to one's job \\
\hline Contextual performance & Extra-role behaviors \\
\hline Achievement of goals or objectives & Extent to which goals or objectives are achieved \\
\hline Competencies & $\begin{array}{l}\text { Attainment of a combination of tacit and explicit knowledge, } \\
\text { behavior, and skills that gives one potential for effectiveness }\end{array}$ \\
\hline \multicolumn{2}{|l|}{ Performance management system activities } \\
\hline $\begin{array}{l}\text { Communication of expectations and } \\
\text { importance of employees' effort }\end{array}$ & $\begin{array}{l}\text { Communicate performance expectations and why effort is } \\
\text { important }\end{array}$ \\
\hline Coaching & Ongoing interactions that focus on improving job performance \\
\hline Feedback & $\begin{array}{l}\text { Provide information on past performance to improve job } \\
\text { performance }\end{array}$ \\
\hline Recognition & Positive reinforcement in response to a desirable behavior \\
\hline Goal setting & Setting goals for the position one currently holds \\
\hline Identification of training needs & Identification of areas in which training is needed \\
\hline Individual development plans & $\begin{array}{l}\text { Personal and professional growth plans to enhance skills, } \\
\text { behaviors, and abilities }\end{array}$ \\
\hline Career planning & Identification and creation of career paths \\
\hline \multicolumn{2}{|l|}{ Structure of performance management systems } \\
\hline Number of formal performance reviews & $\begin{array}{l}\text { Number of planned conversations between employee and } \\
\text { manager about the employee's performance }\end{array}$ \\
\hline $\begin{array}{l}\text { Number of informal performance } \\
\text { reviews }\end{array}$ & $\begin{array}{l}\text { Number of unplanned conversations between employee and } \\
\text { manager about the employee's performance }\end{array}$ \\
\hline Goal alignment & $\begin{array}{l}\text { Aligned employees performance goals with organizational goals } \\
\text { and priorities }\end{array}$ \\
\hline $\begin{array}{l}\text { Link between performance management } \\
\text { and rewards systems }\end{array}$ & $\begin{array}{l}\text { Reward system differentiates rewards based on quality of } \\
\text { performance }\end{array}$ \\
\hline Number of sources of feedback & Number of sources providing performance feedback \\
\hline Participative decision making & $\begin{array}{l}\text { Encourage employees to express their ideas and incorporate } \\
\text { employee feedback when making performance decisions }\end{array}$ \\
\hline
\end{tabular}


Performance measures. A critical component of a performance management system is how performance is evaluated or assessed. Performance is typically evaluated by use of a performance measure, which has been defined as "a variable or metric used to quantify the efficiency or effectiveness of an action" (Olsen et al., 2007, p. 563). The relevance of the performance measures to the employee's actual job performance is one characteristic of the performance management system. In addition, performance can be evaluated by the extent to which employees demonstrate task performance, display contextual performance, achieve goals or objectives, and attain competencies.

Performance measures can evaluate task or contextual performance. Task performance refers to how well an employee performs fundamental technical activities deemed important to his or her job (Borman \& Motowidlo, 1997). For example, rescue operations would be a type of task performance for a firefighter; closing a sale could be task performance for a sales position (Borman \& Motowidlo). Contextual performance, on the other hand, assesses employees' engagement in extra-role behaviors that are not directly job-related but improve the work climate by increasing organizational effectiveness (Borman \& Motowidlo). Contextual behaviors can include helping a colleague complete a task, maintaining enthusiasm when completing tasks, and volunteering to perform extra duties that are not a part of one's normal job tasks (Borman $\&$ Motowidlo). Contextual behaviors improve social communications and reduce tension in the workplace, which facilitates organizational effectiveness (Arvey \& Murphy, 1998).

Employee performance can also be evaluated on the attainment of competencies or achievement of goals. Draganidis and Mentzas (2006) define a competency as "a 
combination of tacit and explicit knowledge, behavior, and skills that gives someone the potential for effectiveness in task performance" (p. 53). Examples of competencies include team leadership, initiative, self-confidence, and flexibility. In performance management systems, organizations may choose to assess employees on competencies the organization deems as important for organizational effectiveness (Draganidis \& Mentzas). Finally, performance can be assessed on the extent to which employees achieve their performance goals or objectives; these goals or objectives are typically specific to each employee's role.

Use of a salesperson position as an example may help illustrate the differences between the different manners in which performance can be evaluated. The task performance of a salesperson could include the ability to close a sale, as this is an essential activity important to a salesperson's job. An example of contextual performance for a salesperson would be giving a fellow employee tips on how to make sales. Although helping another colleague is not directly related to the salesperson's job, this act will help the organization gain more sales and improve the work environment. The competencies employees are evaluated on are more general and ubiquitous for all employees in the organization. For example, the organization may decide that taking initiative is an important competency for employees across the organization to be evaluated on. Evaluation by attainment of a goal could include evaluating salespeople on the extent to which they achieve their quarterly sales quota for a particular product. The attainment of this goal is related to task performance as selling products is an essential 
part of a salesperson's job, however, attaining a goal requires achieving a specific level of performance.

Performance management system activities. Within performance management systems, organizations can use a range of activities designed to improve employee performance. Some activities include clearly communicating performance expectations to employees and informing employees why their performance efforts are important to organizational effectiveness (Biron et al., 2011). Performance management activities also include providing coaching, feedback, recognition, goal setting, identification of training needs, construction of development plans, and career planning.

Coaching, feedback, and recognition are activities that happen within performance management systems. Coaching consists of formal on-going interactions between employees and their superiors with the goal of facilitating individual learning and behavior changes, as well as providing constructive and developmental opportunities to help employees learn how to face complex situations (Lindbom, 2007). Unlike coaching, which typically focuses on future job performance, feedback focuses on providing employees with information about past job performance in order to reinforce desirable behavior or indicate areas for improvement (Hillman, Schwandt, \& Bartz, 1990). Recognition is a type of positive reinforcement given in response to desirable behaviors designed to shape and improve performance; common forms of recognition include special mention in a meeting, a note in a company newsletter, or various gifts (Haines \& St-Onge, 2012). 
Goal setting, identification of training needs, construction of individual development plans, and career planning are performance management activities that serve as mechanisms to help employees achieve their performance and career goals. Performance management systems can include the activity of setting performance goals for employees for the position they currently hold (Roberts, 2003). In addition, performance management systems can be a useful tool to identify areas in which employees need training to help them achieve their performance goals (Armstrong \& Baron, 2000). Performance management systems can facilitate the construction of individual development plans that influence an employee's personal and professional growth by enhancing skills, behaviors and abilities needed both in current and future job positions. Furthermore, performance management systems can also incorporate career planning for employees to help them identify and work toward career paths (Fey, Bjorkman, \& Pavlovskaya, 2000).

Structure of performance management systems. The structure of the performance management system denotes its design and formation. Structural characteristics of performance management systems include the number of formal performance reviews, the number of informal performance reviews, goal alignment, the presence of a clear link between the performance management system and the organization's rewards system, sources of feedback, and participative decision making.

Some structural characteristics of a performance management system include the number of formal and informal performance reviews. Formal performance reviews refer to planned face-to-face meetings between employees and their supervisors to discuss the 
employee's job performance or development (Dewettinck \& Dijk, 2013). Formal performance reviews serve as a medium to inform employees about how their performance has been evaluated. On the other hand, informal performance reviews are unplanned encounters between a supervisor and his or her employee to discuss the employee's job performance and provide feedback that helps the employee meet performance expectations set in formal performance reviews (Dewettinck \& Dijk).

Goal alignment and the presence of a clear link between the performance management system and the organization's reward system are two other structural components of performance management systems. Goal alignment refers to the extent to which employees' performance goals are explicitly aligned with organizational goals and priorities; goal alignment is believed to help employees understand how their work relates and contributes to the organization's goals and priorities (Enriquez, McBride, \& Paxton, 2001). The presence of a clear link between the performance management system and the rewards system implies that the system should connect to the organization's reward system as a way to differentiate rewards based on the quality of employee performance (de Waal \& Counet, 2008). For example, employees determined to be top performers by the performance management system should benefit more from the rewards system compared to low performers.

Another structural characteristic of performance management systems is the sources organizations use to collect performance data. Performance management systems can use either single source or multi-source feedback. Single-source performance feedback is collected from a single source, typically a primary supervisor. 
Multi-source performance feedback, on the other hand, is collected by a combination of multiple sources, including subordinates, peers, superiors, and external sources (Brutus \& Brassard 2005; Brutus \& Gosselin 2007; as cited by Haines \& St-Onge, 2012).

The structure of a performance management system also involves the extent to which it allows for participative decision making. Participative decision making refers to the degree to which supervisors encourage employees to express their ideas and use employee feedback when making decisions (Arnold, Arad, Rhoades, \& Drasgow, 2000). In performance management systems, participative decision making involves leaders encouraging employees to voice their ideas surrounding their performance and taking their subordinates' input into consideration when making decisions regarding their subordinates' performance, objectives, or development.

\section{Perceived Effectiveness of Performance Management Systems}

Examining all four categories of performance management system characteristics is important due to the positive impact performance management systems can have on organizations. Performance management systems have been found to contribute to the overall effectiveness of organizations in that they lead to beneficial outcomes at the employee and organizational level (den Hartog, Boselie, \& Paauew, 2004). Namely, performance management systems motivate performance, facilitate employee development, help organizations make administrative human resources decisions (e.g. promotion, terminations), and support the overall business strategy (Lawler, 2003). Furthermore, organizations that manage their employees' performance outperform other organizations that do not manage their employees' performance on various measures, 
including finances and productivity (Armstrong, 2000). In order for organizations to actualize these desirable outcomes, it is essential to know which characteristics of a performance management system are most predictive of organizational effectiveness.

Dewettinck (2008) and Dewettinck and Dijk (2013) have defined performance management system effectiveness as the ability of the system to improve individual employee outcomes, including performance, motivation, collaboration, self-esteem, functioning on the job, and comfort in performing job duties. Other researchers have defined the effectiveness of performance management systems by examining the extent to which they produce beneficial outcomes for the organization. For example, Glennding (2002) and Haines and St-Onge (2012) considered performance management systems to be effective if they lead to the achievement of business goals, improved morale, increased customer satisfaction, better retention, and increased ease in adapting to organizational change.

In addition to actual effectiveness of performance management systems, researchers have also examined perceived effectiveness. Perceived effectiveness of performance management systems is defined as individuals' perception regarding the effectiveness of their performance management system in bringing about desirable organizational and individual employee outcomes. Given that the main goals of performance management systems are to enhance organizational effectiveness and improve employee and organizational performance (DeNisi, 2000), it is important to examine perceived effectiveness of the system as a means to assess how successful the system is. In addition, perceived effectiveness of performance management systems is 
important to measure as the attitudes of employees are expected to mediate the relationship between performance management system characteristics and organizational performance (den Hartog et al., 2004), such that the presence of performance management characteristics increases perceived effectiveness of the system, which in turn leads to increased organizational performance.

Existing research has examined the impact performance management system characteristics have on perceived effectiveness of performance management systems. Specifically, research has explored how the purpose of performance management systems, evaluation of performance, performance management system activities, and structural components of performance management systems influence how effective the system is perceived to be. The following sections summarize and evaluate previous research that has examined the relationship between characteristics of performance management systems and perceived effectiveness of the system.

Purpose of the performance management system. Previous research has investigated the impact the purpose of performance management systems has on perceived effectiveness of the system. Dewettinck and Dijk (2013) revealed that employees were more likely to perceive their performance management system to be effective if its main purpose was to improve employees' ability to monitor, evaluate, and adjust their own performance (development-oriented), compared to laying out clear and challenging goals to help employees perform well (results oriented). Dewettinck (2008) found similar findings, in that human resource professionals reported developmentoriented performance management systems to be effective at increasing employee 
motivation and competency levels. In addition, Dewettinck revealed that a system with a results oriented purpose was unrelated to the system's ability to effectively improve performance at the organizational level. Consequently, both of these studies demonstrate that development-oriented performance management systems are perceived to be more effective than systems with a results oriented purpose. However, both of these studies surveyed individuals solely in Belgium, which decreases the ability to generalize the results to other cultures, such as the United States.

Limited research has examined the impact of administrative purposes on perceived performance management system effectiveness. Lawler (2003) found that survey respondents from 55 Fortune 500 companies, most of whom held positions in human resources, perceived performance management systems to be effective if they helped identify the lowest performing employees for termination. Although Lawler's finding indicates that administrative purposes can impact perceived effectiveness of performance management systems, this study only addressed one kind of administrative purpose.

It should be noted that none of the studies that examined the purposes of performance management systems included all three of the potential purposes. This study aimed to fill these gaps by assessing the impact all three purposes have on the perceived effectiveness of performance management systems and addressing various administrative purposes.

Performance measures. Scarce research has been dedicated to studying the relationship between performance measures and perceived effectiveness of performance 
management systems. Only one study examined one performance measure characteristic; Collins-Camargo, Chuang, McBeath, and Bunger (2014) found that the presence of relevant performance measures made agency directors of non-profits more likely to perceive their performance management system to be effective. This demonstrates that performance should be evaluated with the use of appropriate performance measures that relate directly to the desired outcomes of the job. Although Collins-Camargo et al. demonstrated the importance of the relevance of performance measures on perceived effectiveness of the performance management system, they failed to comprehensively examine all performance measure characteristics. In order to gain an understanding of which performance measure characteristics are most important in enhancing perceived performance management system effectiveness, it is necessary to collectively examine all characteristics in one study.

Performance management system activities. Little prior research has investigated the impact of performance management system activities, such as clearly communicating performance expectations to employees and providing recognition to employees for exceptional performance, on perceived effectiveness of the system. Collins-Camargo et al. (2014) found that the more performance standards were clearly understood by employees, the more likely agency directors perceived their performance management system to be effective. Biron et al. (2011) found similar results in interviews with professionals at world-leading firms that practiced communicating performance expectations clearly to employees. Overall, these findings underscore the 
importance of clearly informing employees of their performance expectations to enhance perceived effectiveness of the performance management system.

Recognizing employees for their demonstration of desired behaviors is another activity previous research has investigated to determine if it contributes to perceived effectiveness of a performance management system. Haines and St-Onge (2012) found that employee recognition had a significant and positive relationship with perceived effectiveness of the system, such that the more recognition employees received, the more likely human resource professionals perceived the system to be effective. However, employee recognition did not explain unique variance in perceived effectiveness of the system when it was examined alongside other characteristics, including the use of multisource feedback. Therefore, additional research must be conducted to further assess the impact employee recognition has on perceived effectiveness of performance management systems.

Structure of performance management systems. In previous research a variety of performance management system characteristics have been examined that focus on the design and structure of performance management systems, including the number of formal performance reviews, the number of informal performance reviews, the presence of a clear link between the performance management system and the reward system, the number of sources for performance feedback, and the presence of participative decision making. Dewettinck and Dijk (2013) uncovered that the more planned (formal) and unplanned (informal) discussions managers had with their subordinates about their performance, the more likely these subordinates perceived the system to be effective. 
Furthermore, the number of unplanned or informal discussions had a stronger impact on perceived effectiveness of the system than did formal performance reviews.

Linking the performance management system and the rewards system is thought to be effective as employees are more likely to display high levels of performance if rewards are tied to performance (Lawler, 2003). Human resource professionals at some of the top Fortune 500 companies commonly stated that they perceived performance management systems to be effective when performance appraisals were tied to salary increases, bonuses, and stock awards (Lawler). Although human resource professionals believe a connection between a reward system and performance is important, no empirical research has explored this relationship. Therefore, further empirical research should be conducted to assess the impact a strong connection between reward systems and performance has on perceived effectiveness of performance management systems.

The extent to which performance management systems allow employees to receive performance feedback from more than one source has also been investigated as a predictor of perceived effectiveness of the system. Haines and St-Onge (2012) found that the use of multi-source feedback did not have a significant relationship with the perceived effectiveness of the system. A potential reason given by Haines and St-Onge to explain the lack of significant findings is that multi-source feedback is not typically integrated into the performance system, such that its presence would not lead to employees perceiving the performance management system as effective. It should be noted that Haines and St-Onge surveyed only individuals from Canada, which decreases their ability to generalize their results to other populations. 
Performance management systems can be designed to allow for employee participation in performance or development decisions and performance evaluation discussions. Dewettinck and Dijk (2013) revealed that the more employees participated in the performance management system, the more likely they were to perceive the system to be effective. This study illustrates the importance of participative decision making for contributing to perceptions of effective performance management system.

Summary. Although a number of studies have examined the relationship between structural performance management system characteristics and perceived effectiveness of the system, no studies have examined a comprehensive list of characteristics simultaneously. This gap has been a reoccurring trend across all four categories of performance management system characteristics and perceived effectiveness of the system. This study was aimed to address this gap by assessing the relationship between a comprehensive set of performance management system characteristics and perceived effectiveness of the system to understand which characteristics offer the strongest unique contributions. Insights gained from examining characteristics comprehensively will help organizations design effective performance management systems that successfully increase organizational effectiveness and organizational and employee performance.

In addition to examining the outcome of perceived effectiveness, this study also investigated the impact performance management system characteristics have on employee engagement. Although the main goals of performance management systems are to increase organizational effectiveness and improve performance, work engagement 
is a more proximal outcome that will precede organizational effectiveness (Gruman \& Saks, 2011). Furthermore, examining how to foster work engagement is important as work engagement acts as a driver for increased performance (Gruman \& Saks). The following section defines work engagement and summarizes existing research that has examined the relationship between performance management system characteristics and work engagement.

\section{Work Engagement}

Work engagement is defined as a "positive and satisfying work-related state of mind that is characterized by vigor, dedication, and absorption" (Schaufeli \& Bakker, 2004, p. 295). Vigor is the physical component of engagement that refers to employees exhibiting high levels of energy and mental resilience in the workplace (Bakker \& Demerouti, 2008). The emotional component of work engagement is dedication, or the sense of significance or enthusiasm employees feel as a result of being completely involved in their work (Bakker \& Demerouti). Lastly, absorption, or the cognitive component of work engagement, is the extent to which employees are concentrated and engrossed in their work (Bakker \& Demerouti).

Employee engagement is an important outcome to examine because it is a critical driver of organizational success (Schaufeli \& Bakker, 2004). For example, work engagement has been found to increase customer satisfaction, profitability, and safety (Bakker \& Leiter, 2010; Harter, Schmidt, \& Hayes, 2002; Harter, Schmidt, Killian, \& Agrawal, 2009; as cited by Kotze, van der Westhuizen \& Nel, 2014). Due to the organizational benefits gained from work engagement, organizations should be interested 
in the manner in which performance management system characteristics influence work engagement.

Kotze et al. (2014) examined the relationship between performance management system characteristics and work engagement. Specifically, they examined the impact of what they referred to as three "categories" of performance management characteristics: empowerment, developmental, and appraisal. Although the characteristics within each category were not explicitly listed, the authors gave examples of some characteristics within each category. The empowerment category consisted of characteristics including managers giving employees control over their job performance. Characteristics in the developmental category included performance management activities designed to develop employees (e.g. feedback, allowing opportunities for training, coaching). The appraisal category included characteristics that referred to the extent to which formal performance appraisals took place.

Kotze et al. (2014) surveyed employees from the vehicle and asset-based finance industry in South Africa to see if the empowerment, developmental, and appraisal categories significantly predicted work engagement. Developmental and empowerment performance management categories were found to significantly predict engagement such that employees reported feeling more engaged when performance management activities developed and empowered them. However, the performance appraisal category was not found to significantly predict engagement. Kotze et al. concluded that performance management characteristics that cultivate a work environment of empowerment and trust and signal that managers are supportive of employees improve employee engagement. 
However, the performance management process of having a performance appraisal did not impact engagement. Overall, these findings suggest that merely conducting performance management does not contribute to employee engagement, but rather it is the manner in which performance management systems are conducted that influences engagement.

Although the study of Kotze et al. (2014) provided evidence that performance management system characteristics influenced employee engagement, their study did not specifically indicate which system characteristics significantly predicted engagement. Rather, the performance management characteristics were combined to create three composite categories. This shortcoming hinders the ability to directly compare performance management system characteristics to one another to assess which ones are the most predictive of employee engagement. Therefore, this exploratory study was designed to fill this gap by comprehensively assessing specific performance management characteristics to determine which ones lead to employee engagement.

\section{Purpose of the Study}

The objective of this study was to uncover the performance management system characteristics that are most predictive of perceived effectiveness of the system and employee engagement. Although prior researchers examined the relationship between some performance management system characteristics and these outcomes, no study has included a comprehensive list of performance system characteristics. This limitation prevents the ability to compare characteristics to determine which are the most influential in enhancing perceived effectiveness of the system and employee engagement. Therefore, 
the purpose of this study is to comprehensively examine specific performance management system characteristics to determine which ones have the greatest positive influence on perceived effectiveness of the system and employee engagement. 


\section{Method}

\section{Participants}

Participants were recruited through the professional network of the researcher and students from the business college at San José State University. A total of 200

individuals responded to the survey on performance management systems. Twenty-three participants were removed because they did not meet the eligibility requirement of being currently employed or previously employed. Eighteen individuals were deleted from the sample due to insufficient data. Therefore, the final sample consisted of 159 respondents. Fifty-five individuals from the final sample were recruited from the professional network of the researcher, and 104 respondents were recruited from a research experience pool within the College of Business at San José State University.

The sample consisted of 71 men and 85 women. As seen in Table 2, the majority of the respondents reported being between 18 and 29 years of age (74.8\%) and being employed in the technology industry (24.5\%). In terms of employee type, $35.8 \%$ of the sample were employed full-time, $50.3 \%$ were employed part-time, $10.7 \%$ were employed as interns, and $2.5 \%$ were employed as contractors. The majority of the sample consisted of individual contributors $(73.0 \%)$, with a smaller portion of the sample being managers $(27.0 \%)$. In regards to tenure, $37.1 \%$ of the respondents reported being employed at their organization for less than a year, $34.6 \%$ for $1-3$ years, $11.3 \%$ for $3-5$ years, $9.4 \%$ for $5-10$ years, $3.1 \%$ for $10-15$ years, and $4.4 \%$ for more than 15 years. 
Table 2

Demographic Characteristics $(N=157$ - 159)

\begin{tabular}{|c|c|c|}
\hline Variable & $n$ & $\%$ \\
\hline \multicolumn{3}{|l|}{ Employee Type } \\
\hline Full time employee & 57 & 35.8 \\
\hline Part time employee & 80 & 50.3 \\
\hline Intern & 17 & 10.7 \\
\hline Contractor & 4 & 2.5 \\
\hline \multicolumn{3}{|l|}{ Management level } \\
\hline Individual contributor & 116 & 73.0 \\
\hline First-line manager & 22 & 13.8 \\
\hline Mid-level manager & 15 & 9.4 \\
\hline Senior-level manager & 3 & 1.9 \\
\hline Executive-level manager & 3 & 1.9 \\
\hline \multicolumn{3}{|l|}{ Tenure } \\
\hline Less than a year & 59 & 37.1 \\
\hline $1-3$ years & 55 & 34.6 \\
\hline $3-5$ years & 18 & 11.3 \\
\hline $5-10$ years & 15 & 9.4 \\
\hline $10-15$ years & 5 & 3.1 \\
\hline More than 15 years & 7 & 4.4 \\
\hline \multicolumn{3}{|l|}{ Industry } \\
\hline Arts, entertainment, and recreation & 8 & 5.0 \\
\hline Education & 13 & 8.2 \\
\hline Finance & 14 & 8.8 \\
\hline Government and public administration & 3 & 1.9 \\
\hline Hotel and food services & 28 & 17.6 \\
\hline Legal services & 2 & 1.3 \\
\hline Retail & 17 & 10.7 \\
\hline Technology & 39 & 24.5 \\
\hline Utilities & 4 & 2.5 \\
\hline Other & 30 & 18.9 \\
\hline \multicolumn{3}{|l|}{ Gender } \\
\hline Female & 86 & 54.1 \\
\hline Male & 71 & 44.7 \\
\hline \multicolumn{3}{|l|}{ Age } \\
\hline 18-29 years old & 119 & 74.8 \\
\hline $30-49$ years old & 29 & 18.2 \\
\hline $50-64$ years old & 11 & 6.9 \\
\hline 65 years and over & 0 & 0.0 \\
\hline
\end{tabular}




\section{Measures}

Performance management system characteristics. The four categories of performance management system characteristics (purpose of the performance management system, performance measures, performance management activities, and structure of the performance management system) were assessed with 40 items combined from a variety of sources. Characteristics that were measured using more than one item were consolidated into one variable by averaging the scores of the items that formed the characteristic. Categories were also consolidated into one variable by averaging scores of the characteristics that formed the category. Although the structure category contained characteristics that were measured with varying response formats, characteristics were standardized before their average scores were combined to form the structure category variable.

Purpose of the performance management system. The purpose of performance management system category was measured with three items $(\alpha=.35)$, one for each characteristic (i.e. results oriented, development-oriented, and administrative purposes), with a 7-point Likert scale with response options ranging from strongly disagree (1) to strongly agree (7). The results oriented characteristic item ("The focus of the performance management system focuses on the results I achieve.") and developmentoriented characteristic item ("The main focus of the performance management system is to help me with my own development.") were adapted from Dewettinck (2008). The administrative purpose item, "The performance management system focuses primarily on 
making administrative decisions (promotions, terminations, pay raises, etc.)," was adapted from Cleveland, Murphy, and Williams (1989).

Performance measures. Performance measures characteristics (relevance of performance measures, task performance, contextual performance, achievement of goals or objectives, and attainment of competencies) were measured using 10 items $(\alpha=.64)$, with a 7-point scale with responses ranging from strongly disagree (1) to strongly agree (7). The relevance of the performance measures to an employee's job performance was assessed with one item ("The performance measures I am evaluated on are relevant to my job."). Task performance was measured with two items $(\alpha=.72)$, one of which was "My performance is evaluated against criteria that match my job responsibilities." Contextual performance was measured with four items $(\alpha=.76)$. An example of an item used to measure contextual performance was "My performance is evaluated on the extent to which I volunteer for additional duties." The achievement of goals or objectives was measured using the item, "My performance evaluation takes into account if I met my objectives." The attainment of competencies characteristic was measured with two items $(\alpha=.75)$, one of which was "My performance is evaluated on behaviors that my organization views as important for successful performance, but are not essential to my job." The items assessing whether an employee's contextual performance was assessed as part of the performance management system were adapted from Van Scotter, Motowildo, and Cross (2000). The remainder of items that measured performance measure characteristics were constructed due to insufficient items on existing scales. 
Performance management system activities. Performance management system activities (clearly communicate performance measures and explain why employee efforts are important, coaching, recognition, goal setting, identification of training needs, construction of development plans, and career planning) were measured using 16 items ( $\alpha$ $=.89$ ), with a 7-point scale with responses ranging from strongly disagree (1) to strongly agree (7).

The extent to which performance expectations were clearly communicated and employees understood why their efforts were important was measured with three items ( $\alpha$ $=.67$ ), which were constructed due to insufficient items on existing scales. An example of an item used to measure this variable was "My performance goals and objectives are clearly communicated to me." Coaching was measured with two items $(\alpha=.72)$ that were created due to insufficient items on existing scales. An example of an item that measured coaching was "My supervisor and I meet regularly to help me face complex situations." Feedback was measured with three items $(\alpha=.86)$, one of which was adapted from Selden and Sowa (2011), while the remaining two items were composed due to insufficient preexisting items. An example of an item that measured feedback was "I receive regular feedback about my performance." Employee recognition was measured using three items $(\alpha=.83)$. One recognition item was adapted from Haines and St-Onge (2012) and the remainder were developed due to insufficient existing items. An example of an item that measured recognition was "When I perform well my performance is recognized in a positive manner." 
The extent to which employees set goals as part of the performance management system was measured with the following item, "The performance management system clearly establishes my performance goals and objectives." This item was created due to insufficient items on pre-existing scales. The identification of training needs was measured with the item, "The performance management system helps to identify areas where I need training," which was created due to insufficient items on existing scales. The construction of development plans was measured with two items $(\alpha=.61)$, one of which was adapted from Fey et al. (2000) and the other was constructed due to lack of sufficient items on preexisting scales. An example of an item that measured the construction of a development plan was "The performance management system helps me to develop individual development plans for myself." Career planning was measured with a single item adapted from Fey et al., "The performance management system assists me with career planning."

Structure of performance management systems. Structural performance management system characteristics (number of formal performance reviews, number of informal performance reviews, goal alignment, clear link between performance management system and rewards system, sources of feedback, and participative decision making) were measured with 12 items $(\alpha=.74)$.

The number of formal performance reviews and number of informal performance reviews were measured with two items adapted from Dewetticnk and Dijk (2013), one item for each characteristic. The number of formal performance reviews was measured with the item, "How often have you discussed your performance with a person from your 
organization that was ordered by your organization (e.g.

appraisal/development/evaluation review)?" The number of informal performance reviews was measured using the item, "How often have you discussed your performance with a superior in an informal manner (e.g. after departmental meetings with your supervisor, during a move, during an informal lunch or drink, when your supervisor drops by your desk unplanned)." The response format for both items utilized an 8-point Likert scale measuring frequency with the following response options: (1) Daily, (2) Weekly, (3) A few times a month, (4) Once a month, (5) Once every 3 months, (6) Twice a year, (7) Once a year, (8) Never. The sources in which employees received feedback from was measured using one item, "I received formal performance feedback from the following sources:" that utilized a check all that apply response format with the following response options: subordinates, peers, my supervisor, other supervisors (excluding my supervisor), and external sources.

The remaining nine items were measured using a 7-point Likert scale with responses ranging from strongly disagree (1) to strongly agree (7). Two items adapted from Ayers (2013) and Harper and Vilkinas (2005) were used to measure the extent to which employees' goals were aligned with organizational and business unit objectives ( $\alpha$ $=.81$ ). An example of an item used to measure goal alignment was "The performance management system explains how my performance goals align with business unit objectives." To measure the presence of a clear link between the performance management system and reward system, three items were used $(\alpha=.62)$, two of which were adapted from Tung, Baird, and Schoch (2011) and one was adapted from 
Jaaskelainen and Roitto (2014). An example of an item used to assess the presence of a clear link between the performance management system and rewards system was "The performance management system clearly links my performance to financial rewards (pay, bonus, etc.)." The extent to which the performance management system allowed for participative decision making was measured with four items $(\alpha=.84)$, which were adapted from Aronld et al. (2000), and Jaaskelainen and Roitto. Examples of items used to measure participative decision making were "My supervisor gives me a chance to voice my opinions in conversations regarding my performance," and "My views are taken into account when developing my performance goals."

Perceived effectiveness of performance management systems. Perceived effectiveness of the performance management system was measured using eight items ( $\alpha$ $=.93$ ) with a 7-point Likert scale from strongly disagree (1) to strongly agree (7). Items assessed the extent to which the performance management system led to positive and desirable outcomes for the organization including improving performance, retention, motivation, making employees feel confident they were doing their job well, made organizational change easier, and contributed to the professional development of employees. All items were adapted from Haines and St-Onge (2012) and Dewetticnk and Dijk (2013). Examples of items used to measure the perceived effectiveness of performance management systems include "The performance management system improves employee retention," "The performance management system at my organization improves individual performance," and "The performance management system at my organization motivates employees." In order to assess perceived 
effectiveness of the performance management system as one variable, the average of all eight items was calculated.

Engagement. Employee engagement was measured using Schaufeli, Bakker, and Salanova (2006) nine-item scale $(\alpha=.92)$ using a 7-point Likert scale with responses ranging from strongly disagree (1) to strongly agree (7). The three dimensions of engagement: vigor $(\alpha=.82)$, dedication $(\alpha=.88)$, and absorption $(\alpha=.72)$ were measured using three items each. An example of an item used to measure vigor was "When I get up in the morning, I feel like going to work." An example item utilized to measure dedication was "My job inspires me." An example item used to measure absorption was "I am immersed in my work." In order to evaluate engagement as a single variable, the average of all of the engagement items were computed.

\section{Procedure}

The survey was administered online to all participants through an online survey tool (Qualtrics). The respondents recruited through the researcher's professional network were asked to take the survey through social media sites and email. A message with a brief synopsis of the study was posted on social media sites and in emails along with an anonymous link to the survey. Individuals who viewed the social media post or email could voluntarily choose whether or not to click the link to the survey to participate.

The respondents from the business college subject pool at San José State University saw a brief description of the survey and an estimate of how long it would take them to complete the survey. Business college students could choose which study to 
participate in from a list of available studies in exchange for course credit. Participants who selected this study were directed towards the survey in the Qualtrics system.

Once directed to the survey in Qualtrics, participants were provided with written instructions. To ensure all participants had the same understanding of performance management systems, the definition of performance management systems was included. The instructions then directed respondents to read each statement and indicate their level of agreement by selecting the appropriate response category based on their current or most recent employment. The instructions assured participants that there were no correct or incorrect answers and encouraged honest and accurate responses. Further, the instructions reminded respondents that their participation was completely voluntary and that their responses would be kept anonymous and confidential.

After reading the instructions, participants were asked to select an option to confirm that they gave their voluntary consent to participate and met the eligibility requirement of being currently or previously employed. Upon this confirmation, participants were led to the start of the survey items. If participants selected the option that indicated they did not wish to participate in the research or that they have never been employed, they were directed to the end of the survey thank you message.

Participants who agreed to participate in the survey first answered the 40 items that related to performance management system characteristics. Second, participants were prompted to respond to the eight items that measured perceived effectiveness of the performance management system. Then participants were asked to answer nine questions that measured the extent to which employees were engaged at work. Lastly, participants 
were presented with the six demographic questions. Once a participant had completed the demographic questions, they were directed to the end of survey thank you message. 


\section{Results}

\section{Descriptive Statistics}

Descriptive statistics, as seen in Table 3, were computed in order to understand variables' central tendency and variability. The purpose, measures, and activity categories had means slightly higher than the midpoint $(M=4.78-5.00)$ with relatively small variability $(S D=.82-1.05)$. Of the nineteen performance management system characteristics with a 7-point scale, $73.7 \%$ had means slightly above the midpoint $(M=$ $4.08-4.97)$ and relatively large standard deviations $(S D=1.23-1.58)$. The three remaining performance management system characteristics that were measured using an alternative scale also had means within one point of the midpoint and relatively large standard deviations. Perceived effectiveness of the performance management system and work engagement had means slightly higher than the midpoint $(M=4.44$ and $M=4.88$ respectively) and relatively large standard deviations $(S D=1.19$ and $S D=1.18$ respectively). Therefore, individuals who participated in the survey perceived their performance management system to be somewhat effective and they were somewhat engaged.

\section{Pearson Correlations}

Perceived effectiveness of performance management systems. Pearson correlations were computed to determine the extent to which the four performance management system categories (purpose, measures, activities, and structure) were related to the perceived effectiveness of employees' performance management systems. 
Table 3

Means and Standard Deviations for Performance Management System Characteristics, Perceived Effectiveness, and Engagement $(N=159)$

\begin{tabular}{|c|c|c|}
\hline Variable & M & SD \\
\hline Purpose & 4.78 & .97 \\
\hline Results oriented & 5.06 & 1.23 \\
\hline Development-oriented & 4.68 & 1.58 \\
\hline Administrative purposes & 4.60 & 1.58 \\
\hline Performance Measures & 5.00 & .82 \\
\hline Relevance of performance measures & 5.46 & 1.25 \\
\hline Task performance & 5.05 & 1.27 \\
\hline Contextual performance & 4.64 & 1.18 \\
\hline Achievement of goals or objectives & 5.42 & 1.30 \\
\hline Competencies & 4.42 & 1.39 \\
\hline Performance management system activities & 4.90 & 1.05 \\
\hline $\begin{array}{l}\text { Communication of expectations and importance of } \\
\text { employees' effort }\end{array}$ & 5.42 & 1.01 \\
\hline Coaching & 4.75 & 1.50 \\
\hline Feedback & 5.05 & 1.40 \\
\hline Recognition & 5.24 & 1.26 \\
\hline Goal setting & 4.97 & 1.39 \\
\hline Identification of training needs & 4.87 & 1.47 \\
\hline Individual development plans & 4.81 & 1.32 \\
\hline Career planning & 4.08 & 1.68 \\
\hline Structure of the performance management system ${ }^{1}$ & .00 & .66 \\
\hline Number of formal performance reviews & 3.39 & 1.95 \\
\hline Number of informal performance reviews & 4.40 & 2.04 \\
\hline Goal alignment & 5.06 & 1.29 \\
\hline $\begin{array}{l}\text { Link between performance management and rewards } \\
\text { systems }\end{array}$ & 4.56 & 1.22 \\
\hline Number of sources of feedback & 2.25 & 1.23 \\
\hline Participative decision making & 5.27 & 1.21 \\
\hline Perceived effectiveness of the performance management system & 4.44 & 1.19 \\
\hline Engagement & 4.88 & 1.18 \\
\hline
\end{tabular}

Note: ${ }^{I}$ Characteristics in the structure category were standardized before combining. 
As seen in Table 4, all four of the performance management system categories had significant positive relationships with perceived effectiveness of the system. The performance management system activities category had the strongest correlation with perceived effectiveness of the system $(r=.75, p<.001)$, such that the more performance management system activities were practiced, the more effective employees perceived their performance management system to be.

Pearson correlations were also measured to determine the extent to which the performance management system characteristics within each category were related to perceived effectiveness of the system. As seen in Table 5, two out of the three characteristics in the purpose category, namely results oriented and development-oriented, had significant positive relationships with perceived effectiveness of the performance management system. Performance management systems with a development-oriented purpose had the strongest relationship with perceived effectiveness of the system $(r=.54$, $p<.001$ ), such that the more performance management systems focused on developing their employees, the more likely employees were to perceive their performance management system to be effective.

Within the measures category, the relevance of performance measures, task performance, contextual performance, and achievement of goals or objectives had significant positive correlations with perceived effectiveness of the performance management system (see Table 6). 
Table 4

Pearson Correlations Among Performance Management System Categories, Perceived Effectiveness of the Performance Management System, and Engagement $(N=159)$

\begin{tabular}{|c|c|c|c|c|c|c|c|c|c|c|c|c|}
\hline & Variable & 1 & & 2 & & 3 & & 4 & & 5 & & 6 \\
\hline 1. & $\begin{array}{l}\text { Purpose of the performance management } \\
\text { system }\end{array}$ & $(.35)$ & & & & & & & & & & \\
\hline 2. & Performance measures & .48 & $* * *$ & $(.64)$ & & & & & & & & \\
\hline 3. & Performance management system activities & .60 & $* * *$ & .73 & $* * *$ & $(.89)$ & & & & & & \\
\hline 4. & $\begin{array}{l}\text { Structure of the performance management } \\
\text { system }\end{array}$ & .52 & $* * *$ & .61 & $* * *$ & .79 & $* * *$ & (.74) & & & & \\
\hline 5. & $\begin{array}{l}\text { Perceived effectiveness of the performance } \\
\text { management system }\end{array}$ & .52 & $* * *$ & .65 & $* * *$ & .75 & $* * *$ & .63 & $* * *$ & (.93) & & \\
\hline 6. & Engagement & .27 & $* *$ & .38 & $* * *$ & .55 & $* * *$ & .51 & $* * *$ & .48 & $* * *$ & $(.92)$ \\
\hline
\end{tabular}


Table 5

Pearson Correlations Among Performance Management System Performance Purposes, Perceived Effectiveness of the Performance Management System, and Engagement $(N=159)$

\begin{tabular}{|c|c|c|c|c|c|c|}
\hline Variable & 1 & 2 & 3 & 4 & & 5 \\
\hline 1. Results oriented & -- & & & & & \\
\hline 2. Development-oriented & $.25 * * *$ & -- & & & & \\
\hline 3. Administrative purposes & .12 & .10 & -- & & & \\
\hline $\begin{array}{l}\text { 4. Perceived effectiveness of the performance } \\
\text { management system }\end{array}$ & $.43 * * *$ & $.54 * * *$ & .09 & (.93) & & \\
\hline 5. Engagement & $.24 * *$ & $.19 *$ & .12 & .48 & $* * *$ & $(.92)$ \\
\hline
\end{tabular}


Of these performance measures characteristics, the extent to which performance was evaluated through contextual performance had the strongest relationship to perceived effectiveness of the performance management system $(r=.54, p<.001)$, such that the more performance was evaluated through the display of extra-role behaviors, the more effective employees perceived their performance management system to be.

All eight of the characteristics in the activities category had significant positive relationships with perceived effectiveness of the performance management system (see Table 7). These characteristics include: clear communication of performance expectations and explanations of why employees' efforts are important, coaching, feedback, recognition, goal setting, identification of training needs, individual development plans, and career planning. The construction of individual development plans had the strongest correlation compared to the rest of the activity characteristics ( $r$ $=.64, p<.001)$. The more performance management systems facilitated the construction of individual development plans, the more effective employees perceived their performance management system to be.

In the structure category, the number of formal performance reviews, the number of informal performance reviews, goal alignment, a clear link between the performance management system and the rewards system, and participative decision making had significant positive relationships with perceived effectiveness of the performance management system (see Table 8). 
Table 6

Pearson Correlations Among Performance Management System Performance Measures, Perceived Effectiveness of the Performance Management System, and Enagement $(N=159)$

\begin{tabular}{|c|c|c|c|c|c|c|c|c|c|c|c|c|c|}
\hline & Variable & 1 & & 2 & & 3 & & 4 & & 5 & 6 & & 7 \\
\hline 1 . & Relevance of performance measures & -- & & & & & & & & & & & \\
\hline 2. & Task performance & .68 & $* * *$ & $(.72)$ & & & & & & & & & \\
\hline 3. & Contextual performance & .30 & $* * *$ & .35 & $* * *$ & $(.76)$ & & & & & & & \\
\hline 4. & Achievement of goals or objectives & .54 & $* * *$ & .60 & $* * *$ & .29 & $* * *$ & -- & & & & & \\
\hline 5. & Competencies & -.13 & & -.07 & & .13 & & .02 & & $(.75)$ & & & \\
\hline 6. & $\begin{array}{l}\text { Perceived effectiveness of the } \\
\text { performance management system }\end{array}$ & .50 & $* * *$ & .50 & $* * *$ & .54 & $* * *$ & .48 & $* * *$ & .11 & $(.93)$ & & \\
\hline 7. & Engagement & .34 & $* * *$ & .34 & $* * *$ & .30 & $* * *$ & .32 & $* * *$ & -.06 & .48 & $* * *$ & $(.92)$ \\
\hline
\end{tabular}

Note. Reliability coefficients are in parentheses along the diagonal. ${ }^{*} p<.05,{ }^{* *} p<.01,{ }^{* * *} p<.001$ 
Table 7

Pearson Correlations Among Performance Management System Activities, Perceived Effectiveness of the Performance Management System, and Engagement $(N=159)$

\begin{tabular}{|c|c|c|c|c|c|c|c|c|c|c|c|c|c|c|c|c|c|c|c|}
\hline & Variable & 1 & & 2 & & 3 & & 4 & & 5 & & 6 & & 7 & & 8 & & 9 & 10 \\
\hline 1. & $\begin{array}{l}\text { Communication of expectations } \\
\text { and importance of employees' } \\
\text { effort }\end{array}$ & $(.67)$ & & & & & & & & & & & & & & & & & \\
\hline 2. & Coaching & .56 & $* * *$ & $(.72)$ & & & & & & & & & & & & & & & \\
\hline 3. & Feedback & 67 & $* * *$ & .77 & $* * *$ & $(.86)$ & & & & & & & & & & & & & \\
\hline 4. & Recognition & .58 & $* * *$ & .62 & $* * *$ & .77 & $* * *$ & $(.83)$ & & & & & & & & & & & \\
\hline 5. & Goal Setting & .61 & $* * *$ & .41 & $* * *$ & .55 & $* * *$ & .49 & $* * *$ & -- & & & & & & & & & \\
\hline 6. & Identification of training needs & .48 & $* * *$ & .32 & $* * *$ & .40 & $* * *$ & .32 & $* * *$ & .41 & $* * *$ & -- & & & & & & & \\
\hline 7. & Individual development plans & .65 & $* * *$ & .63 & $* * *$ & .65 & $* * *$ & .47 & $* * *$ & .59 & $* * *$ & .47 & $* * *$ & $(.61)$ & & & & & \\
\hline 8. & Career planning & .44 & $* * *$ & .53 & $* * *$ & .48 & $* * *$ & .40 & $* * *$ & .44 & $* * *$ & .47 & $* * *$ & .63 & $* * *$ & -- & & & \\
\hline 9. & $\begin{array}{l}\text { Perceived effectiveness of the } \\
\text { performance management system }\end{array}$ & .52 & $* * *$ & .55 & $* * *$ & .62 & $* * *$ & .55 & $* * *$ & .56 & $* * *$ & .53 & $* * *$ & .64 & $* * *$ & .58 & $* * *$ & (.93) & \\
\hline 10. & Engagement & .48 & $* * *$ & .44 & $* * *$ & .48 & $* * *$ & .53 & $* * *$ & .40 & $* * *$ & .24 & $* * *$ & .50 & $* * *$ & .36 & $* * *$ & $.48 * * *$ & $(.92)$ \\
\hline
\end{tabular}

Note. Reliability coefficients are in parentheses along the diagonal. $* p<.05, * * p<.01, * * * p<.001$ 
A clear link between the performance management system and the rewards system had the strongest correlation with perceived effectiveness $(r=.64, p<.001)$, such that the more aligned the performance management system and rewards system were, the more likely employees were to perceive their performance management system to be effective.

Engagement. Pearson correlations were also examined to determine the extent to which the performance management system categories (purpose, measures, activities, and structure) predicted employee engagement. As seen in Table 4, all four performance management system categories significantly and positively predicted employee engagement. However, these correlations were slightly lower compared to the correlations with perceived effectiveness. Similar to the results with perceived effectiveness of the system, the activities category had the strongest relationship with employee engagement compared to the rest of the performance management system categories $(r=.55, p<.001)$.

Pearson correlations were computed to determine the extent to which performance management system characteristics within categories were related to employee engagement. Similar to perceived effectiveness of the system, two out of the three characteristics in the purpose category (results oriented and development-oriented) had significant positive relationships with work engagement (see Table 5). However, unlike perceived effectiveness of the system, performance management systems that focused primarily on the results employees achieve were better able to predict work engagement $(r=.24, p<.01)$ compared to performance management system that focused on developing their employees $(r=.19, p<.05)$. 
Table 8

Pearson Correlations Among Structural Performance Management System Characteristics, Perceived Effectiveness of Performance Management Systems, and Engagement $(N=159)$

\begin{tabular}{|c|c|c|c|c|c|c|c|c|c|c|c|c|c|}
\hline & Variable & 1 & & 2 & & 3 & & 4 & 5 & 6 & & 7 & 8 \\
\hline 1. & Number of formal performance reviews & -- & & & & & & & & & & & \\
\hline 2. & Number of informal performance reviews & .49 & $* * *$ & -- & & & & & & & & & \\
\hline 3. & Goal alignment & .27 & $* *$ & .18 & $*$ & $(.81)$ & & & & & & & \\
\hline 4. & $\begin{array}{l}\text { Link between performance management } \\
\text { and rewards systems }\end{array}$ & .34 & $* * *$ & .32 & $* * *$ & .61 & $* * *$ & $(.62)$ & & & & & \\
\hline 5. & Number of sources of feedback & .29 & $* * *$ & .30 & $* * *$ & .12 & & .13 & -- & & & & \\
\hline 6. & Participative decision making & .27 & $* *$ & .33 & $* * *$ & .39 & $* * *$ & $.54 * * *$ & $.18 *$ & -- & & & \\
\hline 7. & $\begin{array}{l}\text { Perceived effectiveness of the performance } \\
\text { management system }\end{array}$ & .43 & $* *$ & .29 & $* * *$ & .51 & $* * *$ & $.64 * * *$ & .04 & .57 & $* * *$ & $(.84)$ & \\
\hline & Engagement & .20 & $*$ & .30 & $* * *$ & .36 & $* * *$ & $.46 * * *$ & .12 & .56 & $* * *$ & $.48 * * *$ & $(.92)$ \\
\hline
\end{tabular}

Note. Reliability coefficients are in parentheses along the diagonal. ${ }^{*} p<.05, * * p<.01, * * * p<.001$ 
Within the measures category, the same characteristics (relevance of performance measures, task performance, contextual performance, and achievement of goals or objectives) that had significant relationships with perceived effectiveness of the performance management system also had significant positive relationships with employee engagement (see Table 6). Of these characteristics, the relevance of performance measures and task performance were found to have the strongest relationships with work engagement $(r=.34, p<.001$ and $r=.34, p<.001$ respectively), such that the more relevant performance measures were to employees' job and the more employees were evaluated on fundamental elements of their job, the more likely employees were to be engaged.

As with perceived effectiveness of the system, all of the performance management system activities characteristics, including clear communication of performance expectations and explanation of why employees' efforts are important, coaching, feedback, recognition, goal setting, identification of training needs, individual development plans, and career planning had significant positive correlations with employee engagement (see Table 7). Within the activities category, recognition had the strongest relationship with work engagement $(r=.53, p<.001)$, such that the more employees were recognized for their desirable performance, the more likely employees were to be engaged.

The same characteristics in the structure category that had significant positive correlations with perceived effectiveness of the performance management system (the number of formal performance reviews, the number of informal performance reviews, 
goal alignment, a clear link between the performance management system and the rewards system, and participative decision making) were also found to have significant positive correlations with employee engagement. Of the structural performance management system characteristics, participative decision making was found to have the strongest positive correlation with engagement $(r=.56, p<.001)$, such that the more employees were included in discussions and decisions about their performance, the more likely employees were to be engaged.

\section{Standard Multiple Regression Analyses: Perceived Effectiveness}

The purpose of the standard multiple regression analysis was to uncover which performance management system categories and characteristics within each category were most influential in predicting how effective employees perceived their performance management system to be. First, this analysis aimed to determine which of the four performance management system categories (purpose, measures, activities, and structure) were most predictive of perceived effectiveness of the performance management system. Second, this analysis aimed to uncover the characteristics within each category that were most predictive of perceived effectiveness of the performance management system.

Performance management system categories. Given that this research is exploratory and no prior research has provided justification for an order of these categories, a standard multiple regression analysis was conducted with all four categories entered into the analysis simultaneously. As seen in Table 9, the results of this analysis revealed that as a set the purpose of the performance management system, performance measures used to evaluate performance, activities that happen within the performance 
management system, and structural characteristics of the system had a significant relationship with perceived effectiveness of the system, $F(4,154)=55.47, p<.001$. Furthermore, the four performance management system categories explained $59 \%$ of the variance in perceived effectiveness of the system, $\mathrm{R}^{2}=.59, \mathrm{R}^{2}$ adj $=.58$.

Table 9

Standard Multiple Regression Analysis with Performance Management System Categories to Predict Perceived Effectiveness of the Performance Management System $(N=159)$

\begin{tabular}{llll}
\hline \multicolumn{1}{c}{ Variable } & $r$ & $\beta$ & $\mathrm{R}^{2}$ \\
\hline Performance management system categories & & & $.59 * * *$ \\
Purpose of the performance management system & $.52 * * *$ & .10 & \\
Performance measures & $.65 * * *$ & $.22 * *$ & \\
Performance management system activities & $.75 * * *$ & $.48 * * *$ & \\
Structure of the performance management system & $.63 * * *$ & .06 & \\
\hline
\end{tabular}

$* p<.05, * * p<.01, * * * p<.001$

Given that the set of four categories were found to be significantly related to perceived effectiveness of the performance management system, it is important to determine which categories most contributed to this relationship. The performance measures and activities categories were found to have significant unique contributions in explaining variance in perceived effectiveness of the performance management system, such that the more performance management systems emphasized the performance measures employees were evaluated against $(\beta=.22, t=2.94, p<.01)$ and practiced performance management activities $(\beta=.48, t=4.67, p<.001)$, the more effective employees perceived their performance management system to be. These results suggest that although as a set the purpose, measures, activities, and structural performance management system categories significantly explained variance in how effective 
employees perceived their performance management system to be, only the measures and activities category explained unique variance.

Purpose of the performance management system. Although only the performance measures and activity categories were found to explain unique variance in perceived effectiveness of performance management systems, a standard multiple regression analysis was conducted for each category to uncover which characteristics within each category were most predictive of perceived effectiveness of the system. Given that no prior research provided evidence to dictate an order for the purpose characteristics, all three purpose characteristics were entered into the analysis simultaneously. As seen in Table 10, the analysis revealed that performance management systems with a results oriented, development-oriented, and administrative purpose as a set had a significant relationship with perceived effectiveness of the system, $F(3,155)=$ 31.83, $p<.001$. Furthermore, results oriented, development-oriented, and administrative purposes for performance management systems explained $38 \%$ of the variance in perceived effectiveness of the performance management system, $\mathrm{R}^{2}=.38, \mathrm{R}^{2} \mathrm{adj}=.37$.

Table 10

Standard Multiple Regression Analysis with Performance Management System Purposes to Predict Perceived Effectiveness of the Performance Management System $(N=159)$

\begin{tabular}{llll}
\hline \multicolumn{1}{c}{ Variable } & $r$ & $\beta$ & $\mathrm{R}^{2}$ \\
\hline Purpose of performance management systems & & & $.38 * * *$ \\
Results oriented & $.43 * * *$ & $.32 * * *$ & \\
Development-oriented & $.54 * * *$ & $.46 * * *$ & \\
Administrative purposes & .09 & .00 & \\
\hline$* p<.05, * * p<.01, * * * p<.001$ & &
\end{tabular}


Given that the set of three purpose performance management system characteristics were found to be significantly related to perceived effectiveness of the performance management system, it is important to determine which characteristics most contributed to this relationship. Results oriented and development-oriented purposes were found to have positive unique contributions in explaining variance in perceived effectiveness of the performance management system, such that the more performance management systems focused on the results employees achieved $(\beta=.32, t=4.82, p$ $<.001)$ and the development of their employees $(\beta=.46, t=6.99, p<.001)$, the more effective employees were likely to perceive their performance management system to be.

Performance measures. A standard multiple regression analysis was conducted to uncover which characteristics in the performance measures category most strongly influenced how effective employees perceived their performance management system to be. As seen in Table 11, as a set, relevance of performance measures, task performance, contextual performance, achievement of goals or objectives, and attainment of competencies significantly predicted how effective employees perceived their performance management system to be, $F(5,153)=26.46, p<.001$. Furthermore, the five performance management system characteristics related to how performance is evaluated explained $46 \%$ of the variance in perceived effectiveness of the performance management system, $\mathrm{R}^{2}=.46, \mathrm{R}^{2} \mathrm{adj}=.45$. 
Table 11

Standard Multiple Regression Analysis with Performance Measure Characteristics to Predict Perceived Effectiveness of the Performance Management System $(N=159)$

\begin{tabular}{llll}
\hline \multicolumn{1}{c}{ Variable } & $r$ & $\beta$ & $\mathrm{R}^{2}$ \\
\hline Performance measures & & & $.46^{* * *}$ \\
Relevance of performance measures & $.50^{* * *}$ & $.23 * *$ & \\
Task performance & $.50^{* * *}$ & $.12^{* *}$ & \\
Contextual performance & $.54^{* * *}$ & $.36^{* * *}$ & \\
Achievement of goals or objectives & $.48^{* * *}$ & $.18^{*}$ & \\
Competencies & .11 & .09 &
\end{tabular}

$* p<.05, * * p<.01, * * * p<.001$

Within the set of five performance management system measures characteristics, the relevance of performance measures, contextual performance, and achievement of goals or objectives significantly explained unique variance in perceived effectiveness of the performance management system, such that the more employees were evaluated on measures most relevant to their job $(\beta=.23, t=2.69, p<.01)$, extra-role behaviors that increased organizational effectiveness $(\beta=.36, t=5.57, p<.001)$, and the extent to which employees achieved their goals or objectives $(\beta=.18, t=2.40, p<.05)$, the more effective employees perceived their performance management system to be. Although task performance had a significant correlation with perceived effectiveness of the system $(r=.50, p<.001)$, it did not explain unique variance in perceived effectiveness of the performance management system because of its high correlations with relevance of performance measures $(r=.68, p<.001)$, contextual performance $(r=.35, p<.001)$, and goal attainment $(r=.60, p<.001)$. This overlap in variance prevented task performance from offering a unique contribution in explaining variance in perceived effectiveness of the system. 
Performance management system activities. A standard multiple regression analysis was conducted to determine which performance management system activities explained unique variance in perceived effectiveness of performance management systems. As seen in Table 12, the analysis revealed that performance management system activity characteristics, including clearly communicating performance expectations and explaining why employees' efforts were important, coaching, feedback, recognition, goal setting, identification of training needs, construction of individual development plans, and career planning as a set had a significant relationship with perceived effectiveness of the performance management system $F(8,150)=16.25, p$ $<.001$. Furthermore, the eight activity characteristics explained $58 \%$ of the variance in perceived effectiveness of the performance management system, $\mathrm{R}^{2}=.58, \mathrm{R}^{2} \mathrm{adj}=.56$. Table 12

Standard Multiple Regression Analysis with Performance Management System Activities to Predict Perceived Effectiveness of the Performance Management System $(N=159)$

\begin{tabular}{llll}
\hline \multicolumn{1}{c}{ Variable } & $r$ & $\beta$ & $\mathrm{R}^{2}$ \\
\hline Performance management system activities & & & $.58^{* * *}$ \\
$\quad$ Communication of expectations and importance of & $.52 * * *$ & -.11 & \\
employees' effort & & & \\
Coaching & $.55 * * *$ & .05 & \\
Feedback & $.62 * * *$ & .14 & \\
Recognition & $.55^{* * *}$ & .16 & \\
Goal setting & $.56 * * *$ & $.17 *$ & \\
Identification of training needs & $.53 * * *$ & $.21 * *$ & \\
Individual development plans & $.64 * * *$ & $.22 *$ & \\
Career planning & $.58 * * *$ & $.15 *$ & \\
\hline
\end{tabular}
$* p<.05, * * p<.01, * * * p<.001$

Among the set of eight performance management system activities, goal setting ( $\beta$ $=.17, t=2.33, p<.05)$, identification of training needs $(\beta=.21, t=3.26, p<.01)$, construction of individual development plans $(\beta=.22, t=2.47, p<.05)$, and career 
planning $(\beta=.15, t=2.11, p<.05)$ were found to have significant positive and unique contributions in explaining variance in perceived effectiveness of the performance management system. The more performance management systems facilitated goal setting, identified areas in which employees needed training, constructed individual development plans, and conducted career planning for employees, the more effective employees perceived their performance management systems to be. Coaching, feedback, and recognition all had significant positive correlations with perceived effectiveness of the system $(r=.55, p<.001, r=.62, p<.001$, and $r=.55, p<.001$, respectively); in fact, feedback had one of strongest correlations with perceived effectiveness compared to all of the performance management system characteristics. However, these characteristics were not found to explain unique variance in perceived effectiveness of the system due to their overlap with all of the other activity characteristics at the $p<.001$ level.

Structure of performance management systems. A standard multiple regression analysis was conducted to determine which structural performance management system characteristics explained unique variance in how effective employees perceived their performance management system to be. As seen in Table 13, the analysis revealed that structural performance management system characteristics, including the number of formal performance reviews, the number of informal performance reviews, goal alignment, a clear link to the rewards system, sources of feedback, and participative decision making as a set had a significant relationship with perceived effectiveness of the performance management system $F(6,152)=30.42, p$ $<.001$. Furthermore, the six performance management system structure characteristics 
explained $55 \%$ of the variance in perceived effectiveness of the performance

management system, $\mathrm{R}^{2}=.55, \mathrm{R}^{2} \mathrm{adj}=.53$.

Table 13

Standard Multiple Regression Analysis with Structural Performance Management System Characteristics to Predict Perceived Effectiveness of the Performance Management System $(N=159)$

\begin{tabular}{|c|c|c|c|}
\hline Variable & $r$ & $\beta$ & $\mathrm{R}^{2}$ \\
\hline Structure of the performance management system & & & $.55 * * *$ \\
\hline Number of formal performance reviews & $.43 * *$ & $.24 * * *$ & \\
\hline Number of informal performance reviews & $.29 * * *$ & -.01 & \\
\hline Goal alignment & $.51 * * *$ & $.16 *$ & \\
\hline $\begin{array}{l}\text { Link between performance management and rewards } \\
\text { systems }\end{array}$ & $.64 * * *$ & $.32 * * *$ & \\
\hline Number of sources of feedback & .04 & $-.14 *$ & \\
\hline Participative decision making & $.57 * * *$ & $.30 * * *$ & \\
\hline
\end{tabular}

$* p<.05, * * p<.01, * * * p<.001$

Within this category, the number of formal performance reviews $(\beta=.24, t=3.64$, $p<.001)$, goal alignment $(\beta=.16, t=2.25, p<.05)$, clear link to the rewards system $(\beta$ $=.32, t=4.10, p<.001)$, and participative decision making $(\beta=.30, t=4.49, p<.001)$ made significant unique contributions in explaining variance in perceived effectiveness of the performance management system. Therefore, the more planned conversations employees had with their supervisors regarding their performance, employees' goals aligned with their organization's and business unit's goals, the rewards system was clearly linked to the performance management system, and supervisors included employees in discussions and decisions about their performance, the more effective employees perceived their performance management system to be. Although the number of sources of feedback had a significant negative contribution $(\beta=-.14, t=-2.44, p<.05)$, its correlation with effectiveness of the system was not significant $(r=.04, p>.05)$. This, coupled with its low correlations with the other structural characteristics, suggests that 
the number of sources of performance feedback characteristic was able to capture a minuscule amount of unique variance in perceived effectiveness of the performance management system and therefore should not be considered influential in the prediction of perceived effectiveness of the system.

Summary. Overall, the performance management system categories as a set were able to significantly predict perceived effectiveness of the system, however, only the performance measures and activities category were able to significantly explain for unique variance. When examining all of the individual performance management system characteristics as a set by category, the characteristics within the purpose, performance measures, activity, and structure category were significantly able to predict perceived effectiveness of the performance management system.

Within the purpose category, performance management systems that focused on the results employees achieved and the development of employees were found to explain for unique variance in perceived effectiveness of the system. In the performance measures category, performance management systems that evaluated their employees on relevant performance measures, contextual performance, and the achievement of goals or objectives were able to significantly explain for unique variance in perceived effectiveness of the system. Within the performance management system activity category, performance management systems that facilitated goal setting, identified training needs, constructed individual development plans, and helped employees with career planning were found to significantly explain for unique variance in perceived effectiveness of performance management systems. Lastly, in the structure of 
performance management system category, the number of formal performance reviews, goal alignment, the number of sources of performance feedback, and participative decision making were found to significantly explain for unique variance in perceived effectiveness of performance management systems. However, given that the number of sources of performance feedback did not have a significant Pearson correlation with perceived effectiveness of the system this characteristic should not be considered influential in predicting perceived effectiveness of the system.

\section{Standard Multiple Regression Analyses: Engagement}

The purpose of the second set of standard multiple regression analyses was to determine whether the performance management system categories and characteristics within each category were predictive of employee engagement. First, this analysis aimed to determine which of the four performance management system categories were most predictive of employee engagement. Second, this analysis aimed to uncover which characteristics within each category most uniquely related to work engagement.

Performance management system categories. A standard multiple regression analysis was conducted with all four categories (purpose, measures, activities, and structure) entered into the analysis simultaneously. As seen in Table 14, the set of four categories had a significant relationship with employee engagement, $F(4,154)=18.76, p$ $<.001$. Furthermore, the four categories explained $33 \%$ of the variance in engagement, $\mathrm{R}^{2}=.33, \mathrm{R}^{2} \mathrm{adj}=.31$. 
Table 14

Standard Multiple Regression Analysis with Performance Management System Categories to Predict Engagement $(N=159)$

\begin{tabular}{llll}
\hline \multicolumn{1}{c}{ Variable } & $r$ & $\beta$ & $\mathrm{R}^{2}$ \\
\hline Performance management system categories & & & $.33 * * *$ \\
Purpose of the performance management system & $.27 * *$ & -.11 & \\
Performance measures & $.38 * * *$ & -.05 & \\
Performance management system activities & $.55 * * *$ & $.50 * * *$ & \\
Structure of the performance management system & $.51 * * *$ & .20 & \\
\hline
\end{tabular}

$* p<.05, * * p<.01, * * * p<.001$

Only the activities category was found to have a positive unique contribution in explaining engagement $(\beta=.50, t=3.83, p<.001)$, such that the more the performance management system practiced performance management system activities, the more engaged employees were likely to be.

Purpose of the performance management system. A standard multiple regression analysis was conducted by relating the three characteristics within the purpose category (results oriented, development-oriented, administrative purpose) to engagement. As seen in Table 15, the analysis revealed that these three purpose characteristics had a significant relationship with engagement, $F(3,155)=4.65, p<.01$. Furthermore, results oriented, development-oriented, and administrative purposes for performance management systems explained $8 \%$ of the variance in employee engagement $\mathrm{R}^{2}=.08$, $\mathrm{R}^{2} \mathrm{adj}=.07$. 


\section{Table 15}

Standard Multiple Regression Analysis with Performance Management System Purposes to Predict Engagement $(N=159)$

\begin{tabular}{clll}
\hline \multicolumn{1}{c}{ Variable } & $r$ & $\beta$ & $\mathrm{R}^{2}$ \\
\hline Purpose of performance management systems & & & $.08 * *$ \\
Results oriented & $.24 * *$ & $.20 *$ & \\
Development-oriented & $.19 *$ & .13 & \\
Administrative purposes & .12 & .08 & \\
\hline
\end{tabular}

$* p<.05, * * p<.01, * * * p<.001$

Performance management systems with a results oriented purpose were found to have a significant and positive unique contribution in explaining employee engagement $(\beta=.20, t=2.53, p<.05)$, such that the more performance management systems focused on the results employees achieved, the more engaged employees were likely to be.

Performance measures. A standard multiple regression analysis was conducted to uncover which characteristics used to evaluate employees' performance (relevance of performance measures, task performance, contextual performance, achievement of goals or objectives, and obtainment of competencies) most strongly influenced how engaged employees were at work. As seen in Table 16, as a set, the five measures characteristics were found to significantly predict how engaged employees were at work, $F(5,153)=$ $6.92, p<.001$. Furthermore, the five performance management system characteristics dedicated to how performance was evaluated or assessed explained $19 \%$ of the variance in employee engagement, $\mathrm{R}^{2}=.19, \mathrm{R}^{2} \mathrm{adj}=.16$. 
Table 16

Standard Multiple Regression Analysis with Performance Measures

Characteristics to Predict Engagement $(N=159)$

\begin{tabular}{llll}
\hline \multicolumn{1}{c}{ Variable } & $r$ & $\beta$ & $\mathrm{R}^{2}$ \\
\hline Performance measures & & & $.19 * * *$ \\
Relevance of performance measures & $.34 * * *$ & .13 & \\
Task performance & $.34 * * *$ & .11 & \\
Contextual performance & $.30 * * *$ & $.20 *$ & \\
Achievement of goals or objectives & $.32 * * *$ & .12 & \\
Competencies & -.06 & -.06 & \\
$* p<.05, * * p<.01, * * * p<.001$ & &
\end{tabular}

Only evaluating contextual performance was found to explain for unique variance in engagement $(\beta=.20, t=2.47, p<.05)$, such that the more employees' performance was evaluated on extra-role behaviors, the more likely employees were engaged at work. Although the relevance of performance measures, task performance, and achievement of goals had significant positive correlations with engagement $(r=.34, p<.001, r=.34, p$ $<.001$, and $r=.32, p<.001$ respectively), these variables were not found to explain for unique variance in engagement due to their overlap with each other as evidenced by their strong Pearson correlations.

Performance management system activities. A standard multiple regression analysis was conducted to determine which performance management system activities (clearly communicating performance expectations and explaining why employees' efforts are important, coaching, feedback, recognition, goal setting, identification of training needs, construction of individual development plans, and career planning) explained unique variance in employee engagement. As seen in Table 17, the analysis revealed that performance management system activities characteristics as a set had a significant 
relationship with employee engagement $F(8,150)=11.14, p<.001$. Furthermore, the eight activity characteristics explained $37 \%$ of the variance in employee engagement, $\mathrm{R}^{2}$ $=.37, \mathrm{R}^{2} \mathrm{adj}=.34$.

Table 17

Standard Multiple Regression Analysis with Performance Management System Activities to Predict Engagement $(N=159)$

\begin{tabular}{llll}
\hline \multicolumn{1}{c}{ Variable } & $r$ & $\beta$ & $\mathrm{R}^{2}$ \\
\hline $\begin{array}{l}\text { Performance management system activities } \\
\text { Communication of expectations and importance of }\end{array}$ & $.48^{* * *}$ & .14 & $.37 * * *$ \\
employees' effort & & & \\
Coaching & $.44^{* * *}$ & .04 & \\
Feedback & $.48^{* * *}$ & -.11 & \\
Recognition & $.53 * * *$ & $.37 * * *$ & \\
Goal setting & $.40^{* * *}$ & .02 \\
Identification of training needs & $.24 * * *$ & -.07 & \\
Individual development plans & $.50^{* * *}$ & $.29 * *$ & \\
Career planning & $.36 * * *$ & .02 & \\
\hline
\end{tabular}

$* p<.05, * * p<.01, * * * p<.001$

Recognition $(\beta=.37, t=2.33, p<.001)$ and the construction of individual development plans $(\beta=.29, t=2.64, p<.01)$ were found to have significant unique contributions in explaining variance in engagement. The more performance management systems recognized employees for desirable performance and helped employees to construct individual development plans, the more likely employees were to be engaged at work.

Structure of performance management systems. A standard multiple regression analysis was conducted to relate structural performance management system characteristics (number of formal performance reviews, the number of informal performance reviews, goal alignment, clear link to the rewards system, sources of feedback, and participative decision making) to employee engagement. As seen in Table 
18 , the set of structural performance management system characteristics was significantly related to employee engagement $F(6,152)=14.34, p<.001$. Furthermore, the six activity characteristics explained $36 \%$ of the variance in employee engagement $\mathrm{R}^{2}=.36$, $\mathrm{R}^{2} \mathrm{adj}=.34$.

Table 18

Standard Multiple Regression Analysis with Structural Performance Management System Characteristics to Predict Engagement $(N=159)$

\begin{tabular}{llll}
\hline \multicolumn{1}{c}{ Variable } & $r$ & $\beta$ & $\mathrm{R}^{2}$ \\
\hline Structure of the performance management system & & & $.36^{* * *}$ \\
$\quad$ Number of formal performance reviews & $.20^{*}$ & -.05 & \\
Number of informal performance reviews & $.30^{* * *}$ & .12 & \\
Goal alignment & $.36^{* * *}$ & .10 & \\
$\quad$ Link between performance management and & $.46^{* * *}$ & .16 & \\
rewards systems & & & \\
Number of sources of feedback & $.12^{* * *}-.01$ & \\
Participative decision making & $.56^{* * *}$ & $.41^{* * *}$ & \\
\hline
\end{tabular}

$* p<.05,{ }^{* *} p<.01,{ }^{* * *} p<.001$

Of the set of six structural performance management system characteristics, only participative decision making was found to have a significant unique contribution in explaining engagement $(\beta=.41, t=2.24, p<.001)$, such that the more employees were included in conversations and decisions about their performance, the more likely they were to feel engaged.

Summary. Overall, the performance management system categories as a set were able to significantly predict employee engagement, however, only the activities category was able to significantly explain unique variance. When examining the individual performance management system characteristics within each category, the characteristics within all four categories were significantly able to predict employee 
engagement. Within the purpose category, performance management systems that focused on the results employees achieved explained unique variance in employee engagement. In the performance measures category, performance management systems that evaluated their employees on contextual performance were able to significantly explain unique variance in employee engagement. Within performance management system activities, performance management systems that recognized their employees for desirable behavior and helped employees construct individual development plans were found to significantly explain unique variance in employee engagement. Lastly, in the structure of performance management system category, participative decision making was found to significantly explain unique variance in employee engagement. 


\section{Discussion}

Performance management systems have various benefits for organizations, including increased organizational performance (Buchner, 2007) and effectiveness (Cardy, 2004; as cited by Gruman \& Saks, 2011). In order for organizations to put successful performance management systems in place, organizations must understand which system characteristics are most influential in producing positive organizational outcomes. The purpose of this study was to comprehensively examine performance management systems to determine which system characteristics were best able to predict perceived effectiveness of the performance management system and employee engagement.

Results showed that as a set, four performance management system categories (purpose, measures, activities, and structure) significantly explained variance in perceived effectiveness of the performance management system. Among the categories, performance management systems that emphasized measures to evaluate performance and activities that happened within the performance management system were found to be most influential in predicting perceived effectiveness of the performance management system.

Performance management system characteristics within categories were also found to explain significant variance in perceived effectiveness of the system. In the purpose category, employees were most likely to perceive their performance management system to be effective if the system focused on the results employees achieved and the development of the employees. Within the performance measures category, employees 
were most likely to perceive their performance management system to be effective if the system evaluated employees on performance measures that were relevant to their jobs, on extra-role behaviors that increased organizational effectiveness, and the extent to which employees achieved their goals or objectives. Performance management system characteristics in the activities category that were best able to predict perceived effectiveness of the performance management system included goal setting, identifying the training needs of employees, creating individual development plans, and career planning. Within the structure category, employees were most likely to perceive their performance management system to be effective if employees had more planned discussions with their manager about their performance, if employees' goals aligned with their organization's goals, if the rewards system and performance management system were clearly linked, and if managers encouraged their employees to voice their opinions and took employees' ideas into consideration when making decisions about their subordinates' performance.

Similar to results pertaining to perceived effectiveness of the performance management system, as a set, the purpose, measures, activities, and structure performance management system categories significantly predicted employee engagement. Comparing the four categories found that activities that happened within the performance management system were best able to predict employee engagement.

Performance management system characteristics within categories were also found to predict employee engagement. Within the purpose category, employees were most likely to be engaged at work when their performance management system focused 
on the results employees achieved. In the performance measures category, performance management systems that evaluated employees on the extent to which they engaged in extra-role behaviors that increased organizational effectiveness were most likely to increase employee engagement. The performance management system characteristics in the activities category that were best able to predict employee engagement included recognizing employees for desired performance and creating individual development plans for employees. Lastly, in the structure category, employees were most likely to be engaged if their managers encouraged their subordinates to voice their opinions about their performance and took their employees' input into consideration when making decisions about their performance.

\section{Theoretical Implications}

Overall, this study adds to previous literature, as this was the first study to comprehensively examine performance management systems and uncover which performance management system characteristics were most predictive of perceived effectiveness of the system and employee engagement. Further, as part of this research, a scale was created to evaluate performance management systems holistically and individual characteristics within the performance management system. Future researchers who plan to study performance management systems could utilize this scale in their research endeavors.

Perceived effectiveness of performance management systems. This study adds to the current body of literature regarding performance management system characteristics by being the first study to predict perceived effectiveness of the 
performance management system from the following performance management system characteristics: task performance, contextual performance, achievement of goals or objective, obtainment of competencies, coaching, feedback, goal setting, identification of training needs, individual development plans, career planning, and goal alignment. The inclusion of these characteristics allowed one to discover which ones had the most influence in predicting perceived effectiveness of the performance management system.

Several relationships between performance management system characteristics and perceived effectiveness of the performance management system uncovered in this study were consistent with findings in previous research. First, in the measures category, this study corroborated Collins-Camargo et al.'s (2014) finding that employees perceived their performance management system to be more effective when they were evaluated with performance measures that were relevant to their jobs. Further, consistent with Haines and St-Onge's (2012), this study found recognition had a significant correlation with perceived effectiveness of the performance management system; however when it was examined with other system characteristics in a multiple regression analysis, recognition was unable to explain for unique variance in perceived effectiveness of the system.

In the structure category, this study found that the perceived effectiveness of the performance management system was predicted by a clear link between the performance management system and the rewards system, the number of sources of performance feedback, and participative decision making. As a result, this study provided empirical evidence for Lawler's (2003) belief regarding the importance of a strong link between the 
performance management system and the rewards system. Consistent with previous research by Haines and St-Onge (2012), this study also found that the number of sources from which employees received performance feedback was unrelated to how effective employees perceived their performance management system to be, implying that the quantity of sources employees receive performance feedback from may not be important in how effective employees perceive their performance management system to be. Similar to the findings of Dewettinck and Dijk (2013), the more managers encouraged employees to participate in discussions about performance and incorporated employee input when making decisions regarding their subordinates performance, the more likely employees were to perceive their performance management system to be effective.

In addition to consistent findings with previous research, this study also revealed conflicting findings with prior research. Contrary to findings by Dewettinck (2008) and Dewettinck and Dijk (2013), who found performance management systems with a development-oriented purpose were perceived to be more effective than performance management systems with a results oriented purpose, this study revealed that performance management systems that focused on the results employees achieved and the development of employees were both important in predicting perceived effectiveness of the performance management system. These contradictory findings can be explained by the bipolar items Dewettinck (2008) and Dewetticnk and Dijk (2013) used to measures results oriented and development-oriented purposes, such that results- and development-oriented purposes were opposite end points on a single continuum. The present study measured these purposes separately, thereby allowing for the possibility 
that performance management systems could be both results- and development-oriented. Allowing for performance management systems to be results- and development-oriented revealed that both of the purposes were important in predicting how effective employees perceive their performance management system to be.

Further contradictory findings were revealed in the purpose category when examining performance management systems used for administrative purposes. The current study found that performance management systems used primarily for administrative purposes were unrelated to perceived effectiveness of the system. This finding is inconsistent with Lawler (2003), who found that employees were more likely to perceive their performance management system to be effective if the system was used for one administrative purpose (identifying the lowest performing employees). These contradictory findings can be explained by the current study's decision to measure all administrative purposes collectively rather than individually. Consequently, Lawler's (2003) finding suggests that specific administrative purposes may be predictive of perceived effectiveness of the performance management system.

In the structure category, conflicting findings with previous research were uncovered with respect to formal and informal performance reviews. Contrary to previous research by Dewettinck and Dijk (2013), who found that performance management systems with more informal performance reviews were more likely to be perceived as effective than systems with more formal performance reviews, this study found that formal performance reviews were better able to predict perceived effectiveness of the system compared to systems with more informal performance reviews. Formal 
performance reviews may be more predictive of perceived effectiveness of the system than informal performance reviews because planned performance reviews give subordinates an opportunity to have conversations with their manager about their performance. The extent to which informal performance reviews happen could depend on how close a relationship the subordinate has with their manager or whether or not the manager and subordinate work at the same location. Further, frequent planned performance reviews signals to the employee that the organization and the manager are making an intentional effort to manage and improve employee performance. Informal performance reviews may not be influential in predicting perceived effectiveness of the system because they may not appear as intentional acts to manage and enhance performance.

Engagement. In addition to perceived effectiveness of the performance management system, examining employee engagement was important because engagement is a more proximal outcome that will precede the main goals of the performance management system to increase organizational effectiveness and performance (Gruman \& Saks, 2011). This study contributes to current literature by being the first study to relate individual performance management system characteristics to engagement. Although Kotze et al., (2014) examined performance management system categories, they failed to identify characteristics within each category that positively influenced employee engagement.

Similar to the research by Kotze et al. (2014), who found that the developmental performance management system category positively predicted employee engagement, 
the current study found that constructing individual development plans for employees increased employee engagement. In addition, Kotze et al. also uncovered that the empowerment performance management system category increased employee engagement. The current study had consistent findings in that recognition and participative decision making, two characteristics that promote empowerment, were found to increase employee engagement.

Overall, the performance management system characteristics predicted perceived effectiveness of the system more than employee engagement. These results are unsurprising as perceived effectiveness of the performance management system is a more direct outcome of performance management system characteristics, compared to employee engagement.

\section{Practical Implications}

Organizations can use the results of this study to help design and implement successful performance management systems. The performance management system categories and characteristics organizations choose to emphasize in their system may depend on outcomes they are trying to achieve. For organizations that aim to implement an effective performance management system as well as increase employee engagement, they should implement the categories and characteristics in their systems that were found to predict both outcomes. Specifically, organizations should emphasize the various activities that happen within the performance management system. Among the performance management system activities, organizations should ensure their performance management systems are designed to help employees to construct individual 
development plans. These individual development plans should help employees grow personally and professionally by enhancing their skills, behaviors, and abilities needed for current and future job positions.

Organizations looking to increase the effectiveness of their performance management system and enhance employee engagement may also be advised to alter the manner in which they evaluate employee performance. Specifically, organizations should evaluate employees based on the extent to which they engage in contextual performance. Contextual performance consists of extra-role behaviors that help to increase organizational effectiveness, including tackling a project with enthusiasm, helping a colleague with their work assignment, volunteering for extra duties, and maintaining a positive attitude in the office.

To ensure performance management systems are effective and increase employee engagement, organizations should also design their performance management systems to allow for participative decision making between supervisors and their subordinates. To ensure employees are encouraged to voice their ideas about their performance, managers should receive training and planned performance reviews and allot times for employees to voice their thoughts about their performance. Managers should also receive training on how to listen and incorporate employees' input into the decisions managers make regarding employees' performance, objectives, or development. Lastly, organizations should consider designing their performance management system to focus primarily on the results employees achieve; this is because this study found that systems with a results oriented purpose increase perceived effectiveness of the system and employee 
engagement. Organizations should heavily focus on performance outcomes and how employee efforts are helping the organization meet their goals.

In addition to the characteristics found to be significant in predicting perceived effectiveness of the system and engagement, a few additional characteristics that were found to significantly predict perceived effectiveness of the system are worth noting as organizations can implement these characteristics to increase how effective employees perceive their performance management system to be. To achieve an effective performance management system, organizations should design their system to evaluate employee performance on measures that are relevant to the employee's job and the extent to which employees achieve their performance goals or objectives. Organizations should also implement performance management system activities that help employees formulate performance goals for themselves and identify and work towards their career paths. Lastly, organizations should ensure that performance management systems are clearly linked with the rewards system, such that level of performance determined by the performance management system should dictate the amount of rewards employees receive. Employees who display high levels of performance should receive more rewards compared to poor performers.

Organizations that are primarily interested in increasing employee engagement should design their performance management systems to emphasize the categories and characteristics that were found to increase both perceived effectiveness and engagement. In addition, organizations should design their performance management systems to allow for more opportunities to recognize employees for their desired performance. 
Organizations may consider recognizing employees with non-financial rewards including a special mention in a meeting or email, or financial rewards including gift cards or small amounts of cash.

\section{Strengths of the Study}

One of the strengths of this study is that it allowed for the examination of performance management systems comprehensively. The inclusion of all performance management system characteristics in one study was essential to determine which characteristics were most predictive of perceived effectiveness and engagement. The vast majority of individual relationships between system characteristics and perceived effectiveness and engagement were significant. Furthermore, looking at these characteristics as collective sets, which is how they will appear in the workplace, was helpful in uncovering which characteristics most strongly influenced perceived effectiveness of the system and employee engagement.

Another strength of this study was the inclusion of two different desirable outcomes that can result from performance management system characteristics. Perceived effectiveness of the performance management system is a useful measure that examines how valuable the system is as a whole, whereas engagement is one desirable organizational outcome that specifically impacts employees. Measuring both of these outcomes allows organizations to see which characteristics benefit the system as a whole and one desirable outcome that manifests in employees. 


\section{Limitations of the Study and Directions for Future Research}

As with most research, this study has limitations. In order to comprehensively measure all of the performance management system characteristics and avoid survey fatigue, many characteristics were measured with a single item. Measuring variables with a single item limits the reliability and subsequently the validity of these characteristics. Therefore, future researchers should ensure that their performance management characteristics are measured with at least two items.

The fact that participants were drawn from many different organizations limited the ability to control for certain factors that could have potentially impacted the relationship between system characteristics and perceived effectiveness of the system or engagement. For example, the extent to which employees perceived their performance management system to be effective could be influenced by their performance rating. Because performance ratings vary across organizations, it would be impossible to control for performance ratings with a sample drawn from multiple organizations. Although this study chose to sample participants from multiple organizations and industries to increase the generalizability of its findings, future researchers could benefit from drawing participants from one organization to control for variables that might impact the relationship between performance management system characteristics and perceived effectiveness of the system or engagement.

\section{Conclusion}

The successful implementation of performance management systems has the potential to increase organizational performance and effectiveness. However, the lack of 
empirical research on performance management systems limits organizations' knowledge of how to implement performance management systems effectively. This study begins to fill this gap in research and provides organizations with valuable information on which performance management system characteristics to put into effect in order to achieve desirable organizational outcomes. Additional research is encouraged to validate and expand upon the findings of this research to further guide organizations on how to design and implement performance management systems successfully. 


\section{References}

Agarwal, R., Angst, C. M., \& Magni, M. (2009). The performance effects of coaching: A multilevel analysis using hierarchical linear modeling. The International Journal of Human Resources Management, 20, 2110-2134. doi: 10.1080/09585190903178054

Armstrong, M., \& Baron, A. (2000). Performance management. Human resource management (pp. 69-84). Chicago, IL: Heinemann.

Arnold, J. A., Arad, S., Rhoades, J. A., \& Drasgow, F. (2000). The empowering leadership questionnaire: The construction and validation of a new scale for measuring leader behaviors. Journal of Organizational Behavior, 21, 249-269.

Arvey, R. D., \& Murphy, K. R. (1998). Performance evaluation in work settings. Annual Review of Psychology, 49, 141-168.

Ayers, R. S. (2013). Building goal alignment in federal agencies' performance appraisal programs. Public Personnel Management, 42, 495-520. doi: $10.1177 / 0091026013496077$

Bakker, A. B. \& Demerouti, E. (2008). Towards a model of work engagement. Career Development International, 13, 209-223. doi:10.1108/13620430810870476

Biron, M., Farndale, E., \& Paauwe, J. (2011). Performance management effectiveness: Lessons from world-leading firms. The International Journal of Human Resource Management, 22, 1294-1311. doi: 10.1080/09585192.2011.559100

Borman W. C., \& Motowidlo, S. J. (1997). Task performance and contextual performance: The meaning for personnel selection research. Human Performance, 10, 99-109.

Buchner, T. W. (2007). Performance management theory: A look from the performer's perspective with implications for HRD. Human Resource Development International, 10, 59-73. doi: 10.1080/13678860601170294

Cleveland, J. N., Murphy, K. R., \& Williams, R. E. (1989). Multiple uses of performance appraisal: Prevalence and correlates. Journal of Applied Psychology, 74, 130-135.

Collings, D. G., \& Mellahi, K. (2009). Strategic talent management: A review and research agenda. Human Resource Management Review, 19, 304-313. doi:10.1016/j.hrmr.2009.04.001 
Collins-Camargo, C., Chuang, E., McBeath, B., \& Bunger, A. (2014). Private child welfare agency managers' perceptions of the effectiveness of different performance management strategies. Child and Youth Services Review, 38, 133141. http://dx.doi.org/10.1016/j.childyouth.2014.01.019

den Hartog D. N., Boselie, P., \& Paauwe, J. (2004). Performance management: A model and research agenda. Applied Psychology: An International Review, 53, 556-569.

DeNisi, A. S. (2000). Performance appraisal and performance management. Multilevel Theory, Research, and Methods in Organizations: Foundations, Extensions and New Directions (pp. 121-156). San Francisco, CA: Jossey-Bass.

de Waal, A., \& Counet, H. (2008). Lessons learned from performance management system implementations. International Journal of Productivity and Performance Management, 58, 367-390. http://dx.doi.org/10.1108/17410400910951026

Dewettinck, K. (2008). Employee performance management systems in Belgian organizations: Purpose, contextual dependence and effectiveness. European Journal International Management, 2, 192-207.

Dewettinck, K., \& Dijk, H. (2013). Linking Belgian employee performance management system characteristics with performance management system effectiveness: Exploring the mediating role of fairness. The International Journal of Human Resource Management, 24, 806-825. http://dx.doi.org/10.1080/09585192.2012.700169

Draganidis, F. \& Mentzas, G. (2006). Competency based management: A review of systems and approaches. Information Management \& Computer Security, 14, 5164.

Enriquez, V., McBride, J., \& Paxton, L. (2001). Improving knowledge of strategic goals and the impact on organizational commitment. Health Marketing Quarterly, 18, 119-132.

Fey, C. F., Bjorkman, I., \& Pavlovskaya, A. (2000). The effect of human resource management practices on firm performance in Russia. International Journal of Human Resource Management, 11, 1-18.

Giles, W. F., Findley, H.M., \& Field, H.S. (1997). Procedural fairness in performance appraisal: Beyond the review session. Journal of Business and Psychology, 11, 493-506.

Glennding, P. (2002). Performance management: Pariah or messiah. Public Personnel Management, 31, 161-178. 
Gruman, J., \& Saks, A. (2011). Performance management and employee engagement. Human Resources Management Review, 21, 123-136. doi:10.1016/j.hrmr.2010.09.004

Haines, V., \& St-Onge, S. (2012). Performance management effectiveness: Practices or context? The International Journal of Human Resource Management, 23, 11581175. http://dx.doi.org/10.1080/09585192.2011.561230

Harper, S. \& Vilkinas, T. (2005). Determining the impact of an organization's performance management system. Asia Pacific Journal of Human Resources, 43, 76-97.

Harris, M. M., \& Schaubroeck, J. (1988). A meta-analysis of self-supervisor, self-peer, and peer-supervisor ratings. Personnel Psychology, 41, 43-62.

Hillman, L. W., Schwandt, D. R., \& Bartz, D. E. (1990). Enhancing staff members' performance through feedback and coaching. Journal of Management Development, 9, 20-27. http://dx.doi.org/10.1108/02621719010135110

Jaaskelainen, A. \& Roitto, J. (2014). Designing a model for profiling organizational performance management. International Journal of Productivity and Performance Management, 64, 5-27. doi: 10.1108/IJPPM-01-2014-0001

Kranz, G. (2011). Companies draw coaching plays, but managers' skills could be technically foul. Workforce Management, 90, 6.

Kotze, J., Van der Westhuizen, S. \& Elzabe, N. (2014). The relationship between employees' experience of performance management and work engagement within a South African organization. Journal of Psychology in Africa, 24, 475-479. http://dx.doi.org/10.1080/14330237.2014.997027

Lawler, E. E. (1994). Performance management: The next generation. Compensation Benefits Review, 23, 16-19.

Lawler, E. (2003). Reward practices and performance management. Organizational Dynamics, 32, 396-404. doi:10.1016/j.orgdyn.2003.08.007

Lewis, R. E. \& Heckman R. J. (2006). Talent management: A critical review. Human Resource Management Review, 16, 139-154. doi:10.1016/j.hrmr.2006.03.001

Lindbom, D. (2007). A culture of coaching: The challenge of managing performance for long-term results. Organization Development Journal, 25, 101-106.

McCunn, P. (1998). The balanced scorecard. Management Accounting, 76, 34-37. 
Olsen, E., Zhou, H., Lee, D., Ng, Y., Chong, C. C., \& Padunchwit, P. (2007). Performance measurement system and relationships with performance results. International Journal of Productivity and Performance Management, 56, 559-582. doi: 10.1108/17410400710823624

Roberts, G.E. (2003). Employee performance appraisal system participation: A technique that works. Public Personnel Management, 32, 89-97.

Schaufeli, W. B., \& Bakker, A. B. (2004). Job demands, job resources, and their relationship with burnout and engagement: A multi-sample study. Journal of Organizational Behavior, 25, 293-315.

Schaufeli, W. B., Bakker, A. B., \& Salanova, M. (2006). The measurement of work engagement with a short questionnaire. Educational and Psychological Measurement, 66, 701-716. doi: 10.1177/0013164405282471

Selden, S. \& Sowa, J. E. (2011). Performance management and appraisal in human service organizations: Management and staff perspectives. Public Personnel Management, 40, 251-264.

Tung, A., Baird, K., \& Schoch, H. P. (2011). Factors influencing the effectiveness of performance measurement systems. International Journal of Operations \& Production Management, 31, 1287-1310. doi: 10.1108/01443571111187457

Van Scotter, J. R., Motowidlow, S. J., Cross, T. C. (2000). Effects of task performance and contextual performance on systematic rewards. Journal of Applied Psychology, 85, 526-535.

Truss, C., Gratton, L., Hope-Hailey, V., McGovern, P., \& Stiles, P. (1997). Soft and hard models of human resource management: A reappraisal. Journal of Management Studies, 34, 53-73. 